\title{
Steady-state modeling of current loss in a post-hole convolute driven by high power magnetically insulated transmission lines
}

\author{
E. A. Madrid, ${ }^{*}$ D. V. Rose, D. R. Welch, R. E. Clark, and C. B. Mostrom \\ Voss Scientific, LLC, Albuquerque, New Mexico 87108, USA \\ W. A. Stygar, M. E. Cuneo, M. R. Gomez, T. P. Hughes, T. D. Pointon, and D. B. Seidel
Sandia National Laboratories, Albuquerque, New Mexico 87185, USA \\ (Received 22 March 2013; published 17 December 2013)
}

\begin{abstract}
Quasiequilibrium power flow in two radial magnetically insulated transmission lines (MITLs) coupled to a vacuum post-hole convolute is studied at $50 \mathrm{TW}-200 \mathrm{TW}$ using three-dimensional particle-in-cell simulations. The key physical dimensions in the model are based on the ZR accelerator [D. H. McDaniel, et al., Proceedings of 5th International Conference on Dense Z-Pinches, edited by J. Davis (AIP, New York, 2002), p. 23]. The voltages assumed for this study result in electron emission from all cathode surfaces. Electrons emitted from the MITL cathodes upstream of the convolute cause a portion of the MITL current to be carried by an electron sheath. Under the simplifying assumptions made by the simulations, it is found that the transition from the two MITLs to the convolute results in the loss of most of the sheath current to anode structures. The loss is quantified as a function of radius and correlated with Poynting vector stream lines which would be followed by individual electrons. For a fixed MITLconvolute geometry, the current loss, defined to be the difference between the total (i.e. anode) current in the system upstream of the convolute and the current delivered to the load, increases with both operating voltage and load impedance. It is also found that in the absence of ion emission, the convolute is efficient when the load impedance is much less than the impedance of the two parallel MITLs. The effects of space-charge-limited (SCL) ion emission from anode surfaces are considered for several specific cases. Ion emission from anode surfaces in the convolute is found to increase the current loss by a factor of 2-3. When SCL ion emission is allowed from anode surfaces in the MITLs upstream of the convolute, substantially higher current losses are obtained. Note that the results reported here are valid given the spatial resolution used for the simulations.
\end{abstract}

DOI: 10.1103/PhysRevSTAB.16.120401

\section{INTRODUCTION}

A system of magnetically insulated vacuum transmission lines (MITLs) is a key element in a number of present and future pulsed-power systems. MITLs on a multimodule accelerator combine the current from individual generators to drive a common load. These MITL systems are often complex and yet are required to efficiently transmit very high currents under extreme operating conditions. The optimal design of these complex MITL systems must satisfy a number of often competing system-design criteria, including low inductance and minimal current losses [1,2].

Multiple high-power MITLs have successfully been connected using post-hole convolutes on a number of advanced pulsed-power accelerators [3-5]. Here a single post-hole convolute joins a triplate feed by cutting a hole in the middle conductor and joining the outer electrodes with

\footnotetext{
*elizabethm@vosssci.com
}

Published by the American Physical Society under the terms of the Creative Commons Attribution 3.0 License. Further distribution of this work must maintain attribution to the author(s) and the published article's title, journal citation, and DOI.
PACS numbers: 52.65.Rr, 52.58.Lq, 52.59.Mv, 84.70.+p

a post. Figure 1 depicts the power from four individual MITLs being combined into a single final MITL through a double post-hole convolute (DPHC). The figure is rendered in the azimuthal plane that bisects the upper and lower anode posts and cathode holes. Dashed lines are used to show the current path connection along the cathode plates outside of this plane. In the absence of any losses, the individual MITL currents add as indicated in Fig. 1 to drive the load with total current $I_{L}=A+B+C+D$, where $A$ is the bound current flowing in MITL A, etc.

The vacuum sections of the Z [3-18] and ZR [19-25] accelerators have been successful, providing efficient, high-current delivery from the generator to a variety of loads. On ZR, the upstream transmission lines are $3 \mathrm{~m}$ in diameter, the DPHC begins at a radius of approximately $11 \mathrm{~cm}$, and the final radial transmission line begins at a radius of $\sim 5 \mathrm{~cm}$. A schematic of the ZR MITL-convolute system is shown in Fig. 2.

Electrons are emitted from the MITL cathodes wherever the electric field at the cathode exceeds $\sim 240 \mathrm{kV} / \mathrm{cm}$ [26]. At $Z$ and $Z R$ peak operating levels with load currents up to $26 \mathrm{MA}$ and load voltages up to $6 \mathrm{MV}[21,27]$, magnetic insulation of emitted electrons results in a portion of the 


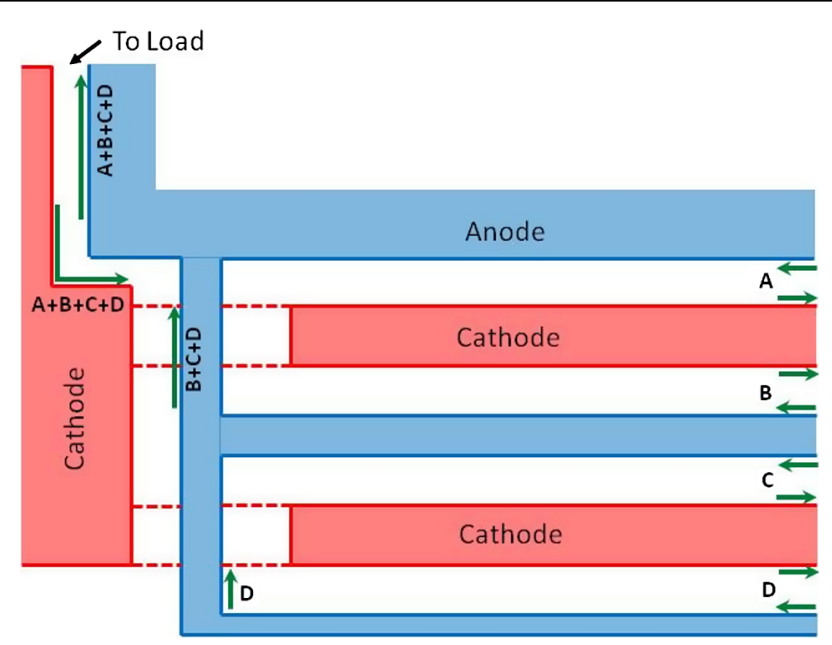

FIG. 1. Schematic of the current flow in an idealized DPHC, showing bound current flow directions and current addition from the four MITLs (A-D) (after T. D. Pointon, et al. Ref. [4]). The dashed lines indicate cathode current connections outside the plane of the figure.

cathode current being carried in a sheared $\boldsymbol{E} \times \boldsymbol{B}$ flow within the anode-cathode (AK) gap [28]. On ZR the AK gaps of the four radial MITLs upstream of the convolute are tapered at relatively large distances from the convolute to obtain constant impedance profiles. At a radius of $\sim 20 \mathrm{~cm}$, the MITLs transition from tapered lines to have a constant $1 \mathrm{~cm}$ AK gap. It is necessary to avoid very small gaps for radii $<20 \mathrm{~cm}$ due to electrode plasma formation and drift which can eventually result in AK gap closure [29-32]. The transition from a tapered, constant impedance gap to a

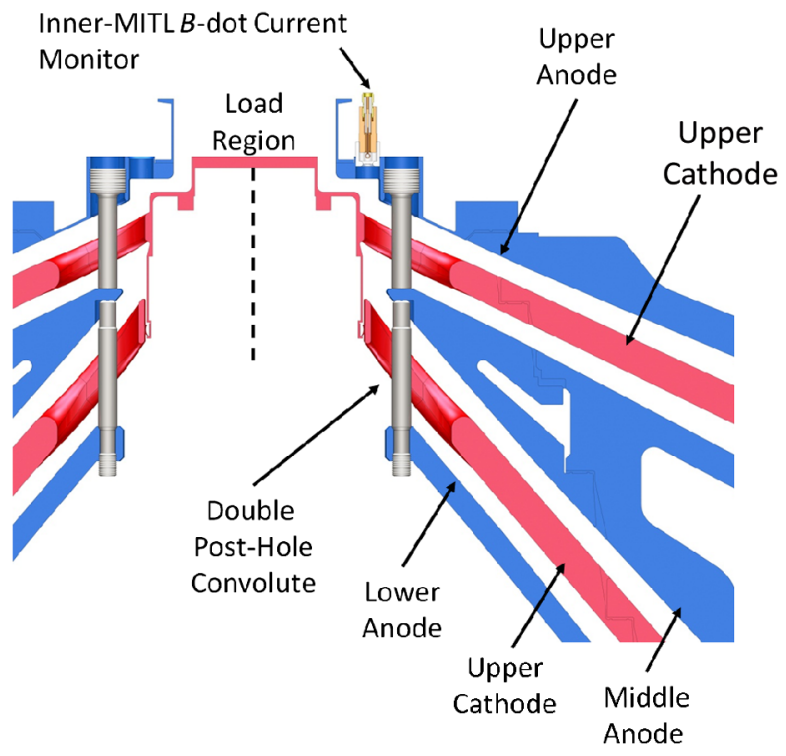

FIG. 2. Schematic of the ZR MITL-convolute system. The anode components are shown in blue (except for the gray anode posts) and the cathode components are shown in red. The dashed vertical line indicates the axis of rotational symmetry for the machine. uniform radial gap results in an increasing vacuum impedance that causes sheath "lift off" and drives quasiperiodic structures (vortices) in the electron flow [17,21,33]. The constant AK gap MITLs then connect to the DPHC, which represents an additional change in impedance. As the sheath approaches and enters the DPHC, it is disrupted $[4,16]$, resulting in most of the electron current being lost to the anode structures.

MITL currents on ZR are measured at two radial locations in the vacuum section. The outer MITL current is measured by $B$-dot monitors that are located in all four MITLs at radii of $\sim 65 \mathrm{~cm}$; the inner MITL current (also referred to as load current) is measured downstream of the DPHC at a $\sim 6 \mathrm{~cm}$ radius [24,34]. The measured current loss between these two locations when driving a $z$-pinch load appears to range from 1 to $4 \mathrm{MA}$, depending on the impedance history of the load. Hence the loss appears to be as high as $\sim 20 \%$ of the total outer MITL current [5,25]. Improving the understanding of the current loss that is measured between the outer and inner MITL-current monitors is the principal motivation of the work described in this article.

It is noted that the actual loss can be approximately half the apparent loss, as illustrated by the following example. Consider a shot for which the apparent current loss (MITL current minus load current) is 4 MA. If this loss occurs at the convolute, the effective inductance of the MITLconvolute system is significantly less than it would be if all the currents were delivered to the load. The reduced inductance increases the outer MITL current above the value it would have if there were no loss. If the loss could be eliminated, the load current would be only $\sim 2 \mathrm{MA}$ higher, since in the absence of loss, the effective inductance of the MITL-convolute system would be increased.

Over the last 15 years, the power delivery efficiency of pulsed multiple-level radial transmission lines driving convolutes has been explored both experimentally and theoretically. Experiments carried out on the Saturn generator [5] demonstrated use of a post-hole convolute for efficient energy coupling from multiple radial transmission lines into a single coaxial transmission line. It was recognized even at this early stage that current losses were present. These results and subsequent experiments prompted theoretical studies, primarily numerical simulations $[4,16,35]$, into the possible causes of these losses. A number of physical mechanisms have been considered. These include the following:

(a) Electron current losses through magnetic field nulls.The geometric configuration of the convolute results in bifurcating current paths that lead to the formation of magnetic field nulls that connect the cathode and anode hardware inside the convolute. Electron flow along these magnetic field nulls can lead to a reduction in the current delivered to the load. Originally analyzed in 3D electromagnetic (EM) particle-in-cell (PIC) simulations [4,5,16,17], this mechanism was not generally found to produce sufficient current losses to explain the measured values. 
(b) Anode ion emission.-Ohmic heating and heating due to electron bombardment along anode components can result in plasma formation. Ions can then be accelerated out of these anode plasmas, leading to additional electron current losses. Three-dimensional EM PIC simulations $[4,18]$ included this effect by enabling ion emission from anode components after local regions of the convolute anode hardware exceeded a threshold temperature. In general, including anode ion emission from these regions did not substantially increase the current loss relative to that from simulations without anode ion emission [36]. These effects are briefly revisited in this work.

(c) Localized electrode plasma expansion leading to resistive short circuits.-Electrode plasmas are known to form in high-power diodes and transmission lines. Jennings et al. [37] carried out a detailed circuit analysis of $\mathrm{Z}$ shot data for wire array loads. They inferred losses from a variety of sources, which included electron MITL current flow, resistive electrode plasma expansion in the convolute, and deposition in the final transmission line between the convolute and load. Using these techniques, an estimate of current loss in the convolute can be obtained for individual shots.

(d) Cathode plasma expansion in the convolute along magnetic field lines.-Plasma formation in and around the holes of the cathodes in the post-hole convolute has been simulated $[27,38]$. For relatively small cathode plasma formation rates, plasma transport along magnetic field lines that are nearly tangential to portions of the cathode edges in the post-holes resulted in accumulation of relatively dense plasma between the anode post and downstream cathodes. The effective gap closure obtained in these simulations resulted in a time-dependent loss channel for electron current. Recent spectroscopic measurements in the ZR convolute region suggest the formation of dense electrode plasmas on the downstream side of the anode posts prior to peak load current [39], which is consistent with the plasma simulation results.

(e) Electrons launched in the MITLs upstream of the convolute.-Electron current sheaths evolving in the MITLs upstream of the convolute may be influenced by a number of nonideal factors such as voltage fluctuations, nonuniform emission sites, and electrode plasma formation/evolution. Even in highly resolved 2D simulations $[21,22,33]$, the electron sheath that forms in the absence of these specific factors is essentially in a nonequilibrium state that includes electron vortex dynamics. The impact of a dynamic nonequilibrium sheath on current loss is investigated in this work.

In addition to these five loss mechanisms, at least three more have been suggested. First, negative ion production in a cathode plasma [29,40,41] can lead to anode plasma formation due to unmagnetized negative ions crossing the AK gap and striking the anode. Second, charge-exchange between neutrals and plasma ions can rapidly increase the plasma layer thicknesses and lead to AK gap closure from the anode electrode $[42,43]$. Finally, microparticle formation [44] may lead to enhanced electrode plasma formation. These additional mechanisms have not been thoroughly explored in 3D convolute simulations and are not considered in this paper.

In this article, fully kinetic, EM, relativistic 3D PIC simulations are used to examine steady-state current losses in an idealized coupled MITL-convolute system. Mechanisms (a), (b), and (e) are addressed along with a number of geometric parameter variations to explore current loss processes. Section II describes the 3D EM simulation model used in this analysis along with the main constraints associated with the model. Section III briefly reviews electron sheath properties. Section IV presents results of the baseline simulation. Loss current scaling with a finite number of parameter variations is examined in Sec. V. These variations include operating voltage, load impedance, cathode hole size, convolute radial location, and anode post size. Sections IV and V assume that the only particles present in the MITL-convolute system are electrons emitted from cathode surfaces throughout the simulation volume. Losses due to both cathode electron and anode ion emission in the system are examined in Sec. VI. A brief summary is presented in Sec. VII.

\section{BASELINE SIMULATION MODEL AND EQUILIBRIUM EM FIELDS}

The PIC code LSP [45] is used to carry out fully kinetic, $\mathrm{EM}$, relativistic 3D $(r, \theta, z)$ simulations to examine electron current losses in an idealized coupled MITL-convolute system. The time step $\Delta t$ is set to resolve both the electroncyclotron $\left(\omega_{\mathrm{ce}}\right)$ and electron-plasma $\left(\omega_{\mathrm{pe}}\right)$ frequencies such that $\left(\omega_{\mathrm{ce}}, \omega_{\mathrm{pe}}\right) \Delta t<2$. Cell sizes throughout the simulation volume are $1 \mathrm{~mm}$ in both the $r$ and $z$ directions, and the azimuthal cell size is fixed at 0.0131 radians. These simulations yield approximate electron sheath dynamics due to this coarse spatial resolution and large macroparticle weights $[18,46]$. For example, the macroparticle weights lead to enhanced space-charge oscillations. This can lead to artificially large nonlinear vortex formation that can momentarily disrupt the sheath. Note that all sheath characteristics need not be fully resolved in these simulations since the primary interest is in modeling the relative current loss channels as electron sheaths flowing along constant-gap radial MITLs interact with the post-hole convolute. Additional comments on underresolved sheaths are presented in Appendix A.

The simulation model is illustrated in Fig. 3. To reduce the time required to complete these studies, a simulation model that explicitly treats the upper two MITLs and upper half of an idealized DPHC system is adopted. The lower two MITLs and post-hole convolute are removed and the corresponding electromagnetic powers are combined and coupled to the upper convolute via a coaxial feed. Hence 


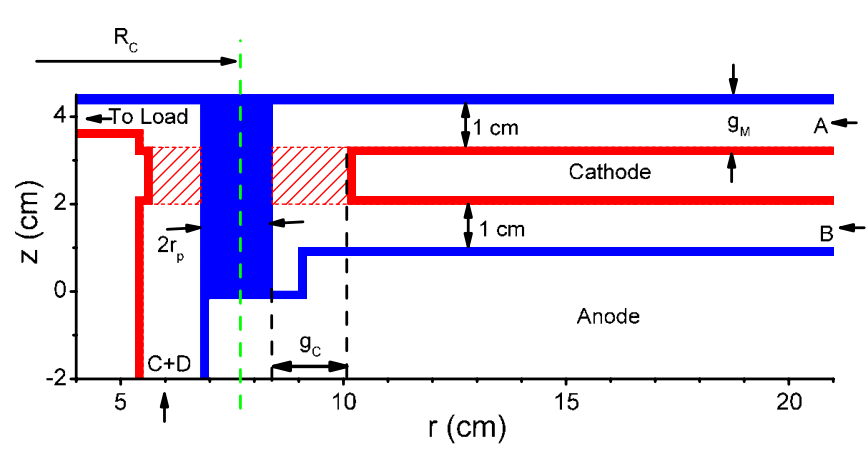

FIG. 3. A 2D schematic of the baseline simulation geometry for the idealized MITL-convolute system in the $\theta=0$ plane, which bisects the anode post and cathode hole. Power is fed in at positions $\mathrm{A}, \mathrm{B}$, and $\mathrm{C}+\mathrm{D}$.

current losses occurring in the lower level MITLs and convolute are not modeled by the simulations described here.

The key physical dimensions used in this coupled MITL-convolute system are based on the ZR accelerator. The simulations use periodic boundaries in $\theta$ and represent one-twelfth of the full system. The simulation region extends radially between $4 \mathrm{~cm}$ and $21 \mathrm{~cm}$. The MITL gaps for levels $\mathrm{A}$ and $\mathrm{B}$ are fixed at $1 \mathrm{~cm}$. The cathode plate separating the two MITL levels is $1.3 \mathrm{~cm}$ thick. The hole in the cathode plate approximates the shape of the upper cathode hole in the ZR convolute. The anode post is $1.6 \mathrm{~cm}$ in diameter. The feed representing the combined power delivered from MITL levels C and D is a coaxial MITL with an inner radius of $5.5 \mathrm{~cm}$ and an outer radius of $6.8 \mathrm{~cm}$. The final radial MITL downstream of the convolute has a $6 \mathrm{~mm}$ gap. This final MITL is terminated by a fixed impedance load, $Z_{L}$, with a baseline impedance of $0.3 \Omega$ (see Appendix B for an assessment of the errors associated with charged particles crossing this boundary). The convolute region of the model $(5.4 \mathrm{~cm}<r<11 \mathrm{~cm})$ has an inductance of approximately $1.4 \mathrm{nH}$.

Simulations are carried out in well-defined temporal phases. In the first phase, forward-traveling voltage waveforms with a $0.5 \mathrm{~ns}$ rise time are introduced into the three input boundaries. These voltages rise linearly from zero and are designed to give an equilibrium voltage and current in the simulation after $\sim 8 \mathrm{~ns}$. The voltage input for the coaxial feed representing MITLs C and D is programmed to deliver 1.9 times more power than in each of MITLs A and $\mathrm{B}$. An additional $2 \mathrm{~ns}$ of run time is allowed to verify an equilibrium state; the first temporal phase is completed in 10 ns. During this time, no particle emission is enabled, a condition henceforth called the cold test. Cold test operating parameters are shown in Table I. Since there are no particles in the simulation during this time there is no current loss.

In the second (or electron-only) phase, electron emission is enabled from all cathode surfaces with an electric field stress greater than $240 \mathrm{kV} / \mathrm{cm}$ [26]. Since the level A and $\mathrm{B}$ radial MITLs have a constant AK gap, a nonuniform vacuum impedance profile exists. The electron sheaths that develop along these MITLs include the formation and propagation of electron vortices. After electron flow current is established, typically requiring $\sim 5 \mathrm{~ns}$, these vortices impact the evaluation of quasiequilibrium operating values. The electron current flow phase of the simulation is run for a minimum of $10 \mathrm{~ns}$ after the turn-on of spacecharge-limited (SCL) electron emission to obtain quasiequilibrium current and voltage values throughout the simulation volume. As illustrated in Table I, the presence of electron space charge in the simulation modifies the operating voltage of the system. This table lists equilibrium values for the voltage $\left(V_{0}\right)$, anode current $\left(I_{A}\right)$ near power feed boundaries, the load current $\left(I_{L}\right)$, and the load impedance $\left(Z_{L}\right)$. Throughout the remainder of this paper, this 5.9 MV electron-only phase result in Table I is referred to as the baseline simulation (indicated in all tables by asterisks in voltage column). Column 6 of Table I lists the loss current fraction $\left[\mathrm{f}_{l}=\left(I_{A}-I_{L}\right) / I_{A}\right]$, which is discussed in further detail below. The last five columns list physical parameters that characterize the simulations: the anode post radius $\left(r_{p}\right)$, the MITL AK gap $\left(g_{M}\right)$, the convolute AK gap $\left(g_{C}\right)$, the convolute radial position $\left(R_{C}\right)$, which is characterized as the distance of the anode post from the machine axis, and the number of posts $\left(N_{p}\right)$.

A third (or electron-ion) phase is included for a select number of simulations where emission of ions is allowed from specific anode regions. This phase starts $10 \mathrm{~ns}$ after electron emission begins. The electron-ion phase typically reaches a quasiequilibrium state $\sim 8 \mathrm{~ns}$ after ion emission begins. Emission of anode ions typically occurs once a conductor surface temperature is increased by $400{ }^{\circ} \mathrm{C}$ [47].

TABLE I. Cold test and electron-only simulation phase details including equilibrium voltage $\left(V_{0}\right)$, load $\left(I_{L}\right)$, and MITL $\left(I_{A}\right)$ currents, load impedance $\left(Z_{L}\right)$, loss current fraction $\left(\mathrm{f}_{l}\right)$, post radius $\left(r_{p}\right)$, MITL AK gap $\left(g_{M}\right)$, convolute AK gap $\left(g_{C}\right)$, convolute radial position $\left(R_{C}\right)$, and number of posts $\left(N_{p}\right)$. Values listed here and in subsequent tables represent time averages and do not reflect uncertainty in measurements. The loss current fractions $\left[\mathrm{f}_{l}=\left(I_{A}-I_{L}\right) / I_{A}\right]$ listed here and in subsequent tables should be multiplied by a factor of $\sim 2$ to obtain an estimate for the loss experienced by a DPHC.

\begin{tabular}{|c|c|c|c|c|c|c|c|c|c|c|}
\hline Simulation phase & $V_{0}(\mathrm{MV})$ & $I_{A}(\mathrm{MA})$ & $I_{L}(\mathrm{MA})$ & $Z_{L}(\Omega)$ & $\mathrm{f}_{l}$ & $r_{p}(\mathrm{~cm})$ & $g_{M}(\mathrm{~cm})$ & $g_{C}(\mathrm{~cm})$ & $R_{C}(\mathrm{~cm})$ & $N_{p}$ \\
\hline cold & 6.1 & 20.68 & 20.68 & 0.3 & $0.0 \%$ & 0.8 & 1.0 & 1.7 & 7.6 & 12 \\
\hline electron & $5.9^{*}$ & 20.19 & 19.48 & 0.3 & $3.5 \%$ & 0.8 & 1.0 & 1.7 & 7.6 & 12 \\
\hline
\end{tabular}

${ }^{*}$ Baseline simulation. 
(a) $\theta=0$

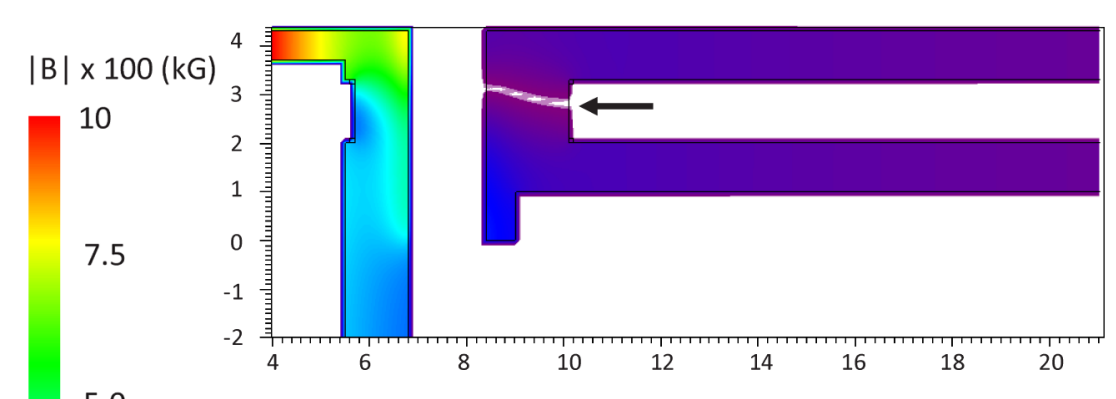

5.0 (b) $\theta=15^{\circ}$
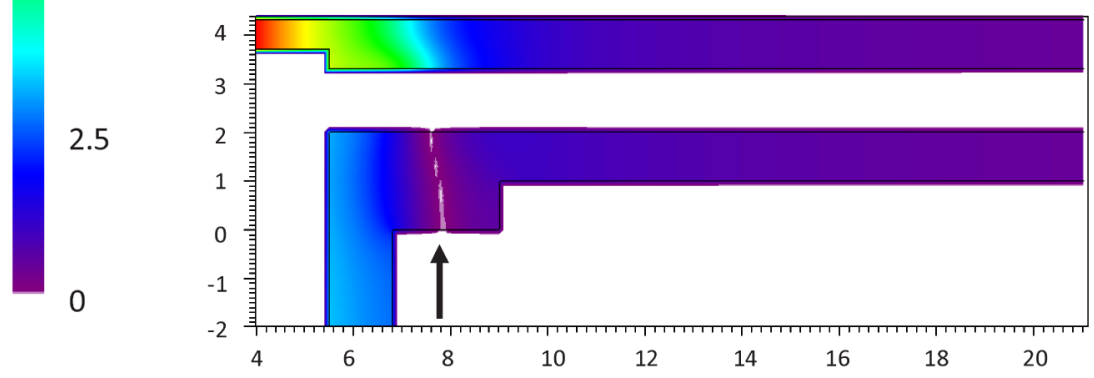

FIG. 4. Two views of the magnetic field magnitude. Field nulls are indicated by arrows and occur in the (a) $\theta=0$ plane and the (b) $\theta=15^{\circ}$ plane.

In the simulation model, ion emission is enabled either by tracking electron energy deposition and subsequent temperature increase or by manually selecting emitting surfaces.

These simulations have a level of uncertainty associated with the statistical nature of the PIC simulation model. Separate tests of spatial resolution and particle number suggest uncertainties of up to $\pm 0.5 \%$ for the loss current fraction results reported here. Values reported in Table I (and subsequent tables) are time-averaged and do not include individual assessments of the uncertainty.

Regions of strongly reduced magnetic field amplitude, or nulls, occur at two locations due to the MITL-convolute current paths shown in Fig. 1. These field nulls are indicated in Fig. 4. The horizontal null shown in Fig. 4(a) connects the edge of the cathode hole to the anode post in the $\theta=0$ plane on the upstream side of the convolute. The vertical null shown in Fig. 4(b) occurs in the $\theta= \pm 15^{\circ}$ plane that is located midway in azimuth between adjacent post-hole convolutes.

The low ratio of plasma to magnetic field pressure of the sheath causes many electrons to execute orbits in the coupled MITL-convolute system along Poynting vector streamlines. Figure 5 plots sample streamlines originating in both the A and B MITLs, continuing through the convolute, and exiting out of the final MITL. Upstream of the convolute, in the absence of fluctuating EM fields, electrons drift along these straight lines. As the streamlines from the level A MITL approach the convolute region, the lines that have paths passing near or over the hole in the cathode plate bend and curve around the anode post. Only streamlines originating very near the $\theta=0$ plane enter the horizontal magnetic field null and terminate on the upstream side of the anode post. This supports the observation, described in the next section, that MITLlaunched electron transport through the magnetic field nulls represents a small but finite portion of the current loss in the simulations.

Streamlines that travel on or near the periodic boundaries at $\theta= \pm 15^{\circ}$ have a relatively small azimuthal variation as they approach and travel past the convolute region.

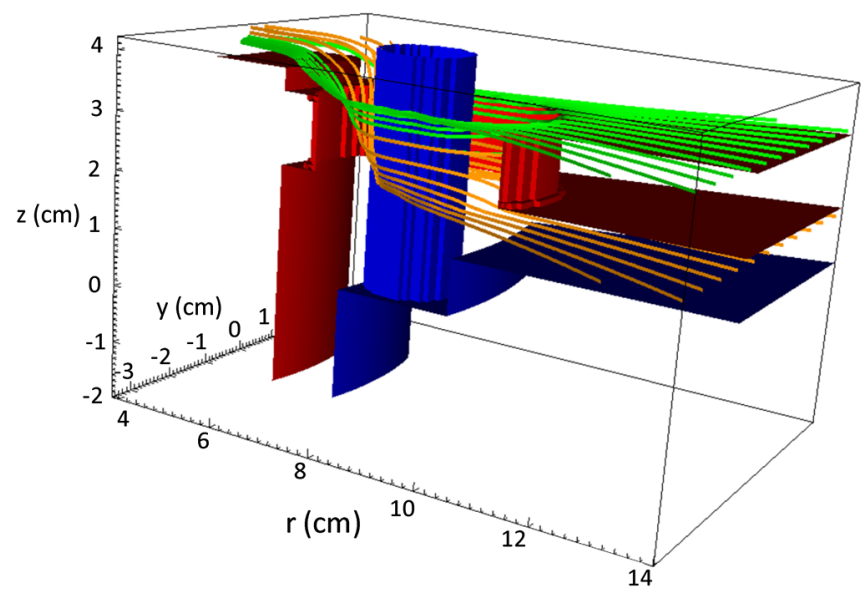

FIG. 5. Poynting vector streamlines indicating the approximate electron drift motion for electrons launched in the MITLs upstream of the convolute in levels A (green streamlines) and B (orange streamlines). Anode surfaces are shown in blue and cathode surfaces are shown in red. The upper anode plate and an azimuthal section of the cathode are removed in this image to show the streamlines more clearly. 
As these streamlines approach the step from the level A MITL gap to the final MITL, the streamlines cross the AK gap traveling into the final MITL section near the anode surface. A portion of the lines nearest to the cathode, however, bend downward and return to the cathode between $r=6.3 \mathrm{~cm}$ and $7.3 \mathrm{~cm}$. Charge deposition is observed in this region and identifies the location between the holes in the convolute as a modest sheath current retrapping [48] region.

As the streamlines from MITL B in Fig. 5 approach the convolute region, they travel upward $(+z$ direction) into and through the cathode hole on the downstream side of the anode post. This vertical trajectory through the convolute carries the level B sheath electrons past the final cathode and very close to the upper anode. The level B and level A streamlines converge in the final radial MITL that connects to the load. Note that the majority of these streamlines are nearer to the anode, rather than the cathode, consistent with previous 3D EM convolute simulations [4,16,27,38] that show the electron current flow traveling along the anode rather than the cathode in the final MITL.

\section{ANALYTIC ESTIMATES OF ELECTRON SHEATH PROPERTIES}

An estimate of the sheath current in a radial transmission line is given by $[4,18,49]$ :

$$
I_{S}(A) \cong \frac{V^{2}}{2 I_{A} Z_{v}^{2}}=1.4 \times 10^{-4} \frac{V^{2} r^{2}}{I_{A} d^{2}},
$$

where $Z_{v}$ is the MITL characteristic impedance $(\Omega), V$ is the voltage $(\mathrm{V}), r$ is the radius (m), $d$ is the AK gap (m), and $I_{A}$ is the current flowing along the anodes (A). Equation (1) yields an expected sheath current of $\sim 210 \mathrm{kA}$ at a radius of $15 \mathrm{~cm}$ with a $1 \mathrm{~cm} \mathrm{AK}$ gap operating at $5.9 \mathrm{MV}$ and 5.2 MA. The baseline simulation yields a single MITL sheath current of $\sim 340 \mathrm{kA}$. This value is approximately $60 \%$ more than predicted by Eq. (1).

As discussed in Ref. [18], an estimate for an equilibrium electron sheath thickness $\left(\propto E / B^{2}\right)$ in a radial line is

$$
d_{s}(m) \cong \frac{142 V r^{2}}{I_{A}^{2} d} \text {. }
$$

For the baseline simulation, Eq. (2) predicts a sheath thickness of $7 \times 10^{-3} \mathrm{~cm}$ at a radius of $15 \mathrm{~cm}$. The sheath thickness in the simulation is $\sim 0.2 \mathrm{~cm}$, which is approximately 30 times larger than that given by Eq. (2) due to the $1 \mathrm{~mm}$ resolution used for the simulations. Equation (2) suggests a minimum simulation grid requirement in the transverse $(z)$ direction on the order of $10 \mu \mathrm{m}$ to resolve sheath dynamics. While this resolution is not practical, the simulated sheath current is a good approximation to Eq. (1). Better sheath resolution can be obtained in 2D simulations for the axisymmetric region upstream of the convolute which shows agreement with Eqs. (1) and (2) [33].
Throughout this paper, the loss current fraction, $\mathrm{f}_{l}=$ $\left(I_{A}-I_{L}\right) / I_{A} \approx I_{S} / I_{A}$, is used as a quality parameter in the analysis and for comparison between the simulation results. Using Eq. (1) and $V=I_{L} Z_{L}$, this fraction can be written as

$$
\mathrm{f}_{l} \approx \frac{Z_{L}^{2} I_{L}^{2}}{2 I_{A}^{2} Z_{v}^{2}},
$$

emphasizing the impact of $Z_{L}$ and $I_{L}$ on the loss current fraction.

A collisional sheath model [50] has been developed that includes the impact of effective collisions (e.g., EM fluctuations, etc.) to thicken the sheath beyond the estimate provided by Eq. (2). The collisional loss current fraction can be expressed as [50]

$$
\mathrm{f}_{l} \approx \frac{9 Z_{L}^{2} I_{L}^{2}}{8 I_{A}^{2} Z_{v}^{2}},
$$

which gives a fractional loss current estimate that is a factor of 2.25 larger than predicted by Eq. (3) but has the same functionality.

\section{BASELINE SHEATH DYNAMICS UNDER QUASIEQUILIBRIUM CONDITIONS}

Simulations are followed over time scales that include multiple vortex formation and propagation times through the system. Vortex formation along the MITLs is a quasiperiodic process that results in a portion of the electron charge from the sheath extending further into the gap. Upstream of the convolute the vortices are azimuthally uniform and continuous. The size and propagation speed of these vortices varies somewhat and it is often seen that a larger vortex propagates at a faster speed than its smaller neighbors. This can result in one vortex overtaking and merging with another as they propagate along the MITL towards the convolute. Figure 6 plots the (a) electron number density and (b) macroparticle positions for the baseline $V_{0}=5.9 \mathrm{MV}, Z_{L}=0.3 \Omega$ simulation at $t=17 \mathrm{~ns}$ in the $\theta=0$ plane. The presence of a nonuniform sheath density profile in the MITLs upstream of the convolute indicates the presence of vortices. The particle position plot in frame (b) shows that electrons can cross to the anode post through the magnetic field null described in the previous section. Electrons shown downstream of the anode post originate from azimuthal positions other than $\theta=0$ upstream of the convolute and have gained an azimuthal velocity component that causes them to pass through the $\theta=0$ plane in this plot.

Once quasiequilibrium power flow conditions are established, the current flowing in the conductors is measured at $1 \mathrm{~cm}$ intervals throughout the radial extent of the simulation. Figure 7 plots the simulated equilibrium anode $\left(I_{A}\right)$, cathode $\left(I_{K}\right)$, and sheath $\left(I_{S}=I_{A}-I_{K}\right)$ current magnitudes as a function of radius. Frames (a) and (b) show 


$\begin{array}{ccccc}\mathrm{n}_{\mathrm{e}}\left(\mathrm{cm}^{-3}\right) 0 & 5.17 \times 10^{3} & 2.67 \times 10^{7} & 1.38 \times 10^{11} & 7.14 \times 10^{14} \\ \mathrm{E}(\mathrm{MeV})_{0} & 1.5 & 3.0 & 4.5 & 6.0\end{array}$

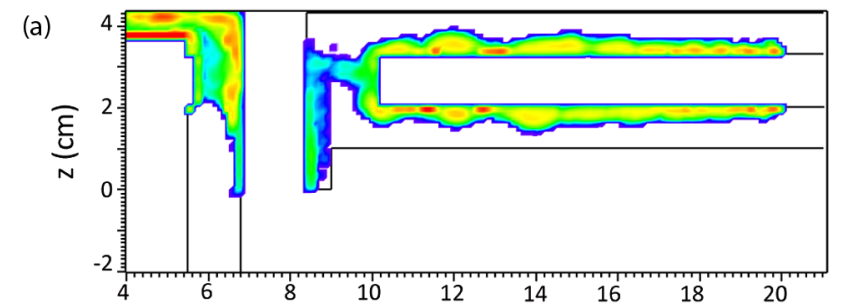

(b)

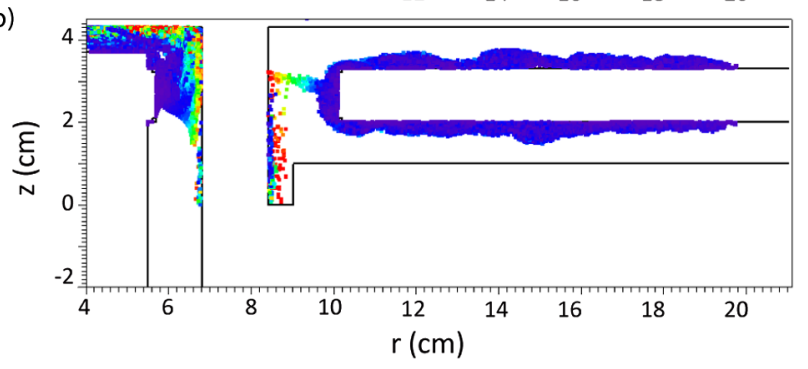

FIG. 6. (a) Electron sheath density $\left(n_{e}\right)$ and (b) particle positions (E, particles colored by total kinetic energy) during quasiequilibrium conditions for the $V_{0}=5.9 \mathrm{MV}, Z_{L}=0.3 \Omega$ simulation in the $\theta=0$ plane.

the anode and cathode currents in MITLs A and B, respectively. In these views it is evident that current flow through the MITLs is essentially constant. Frame (c) shows the total anode and cathode currents from the A and B MITLs as well as the total sheath current (black line). The solid black line with data points shows the total sheath current established upstream of the convolute with a value of roughly $630 \mathrm{kA}$. The dashed black line shows the total sheath current that includes the impact of the coaxial feed in the convolute region. The sheath current falls linearly between $r=10 \mathrm{~cm}$ and $r=4 \mathrm{~cm}$ to a final value of $\sim 125 \mathrm{kA}$. This decrease in the sheath current with decreasing radius is due both to electron losses to anode components (about 85\%) and electron retrapping to cathode components (about 15\%). This result is consistent with those reported previously [3,15-18].

The sheath that evolves in the MITLs upstream of the convolute includes electron heating well beyond what is nominally obtained in a 2D simulation $[20,23,46]$. This heating is attributed to orbit crossings that drive spacecharge oscillations along the magnetic field lines $\left(B_{\theta}\right)$, a 3D effect. The magnitude of this effect needs to be assessed more carefully in a future study. This heating, as well as other effects (both physical and numerical) result in an electron sheath state that may be roughly correlated with nonideal conditions present in the Z MITLs including cathode plasma evolution, surface defects, etc., that can drive turbulence in the electron sheath upstream of the convolute (see, for example, Ref. [5]). Figure 8 compares the equilibrium $v_{r}$ and $v_{\theta}$ electron velocity distributions in the level A MITL for $13<r<17 \mathrm{~cm}$, at $22 \mathrm{~ns}$. These two

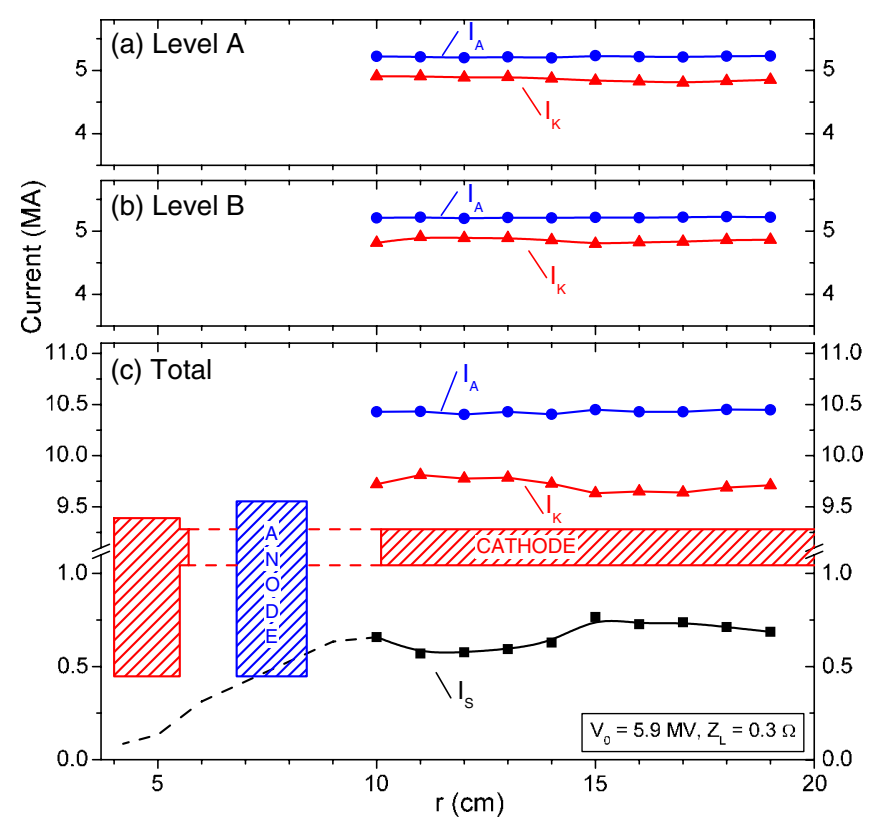

FIG. 7. Current amplitudes in the coupled MITL-convolute baseline simulation as a function of radius in (a) MITL A, (b) MITL B, and (c) the entire system. The blue lines are the anode currents $\left(I_{A}\right)$, the red lines are the cathode currents $\left(I_{K}\right)$, and the black line is the electron sheath current $\left(I_{S}\right)$. These results are for an equilibrium voltage $\left(V_{0}\right)$ of $5.9 \mathrm{MV}$, and a fixed load impedance $\left(Z_{L}\right)$ of $0.3 \Omega$. The diagram in (c) is a schematic of the coupled MITL-convolute system indicating the radial position of the convolute hole and post.

distribution functions are essentially equal as the electron sheath enters the convolute, illustrating a strong growth in the $v_{\theta}$ distribution despite modest fluctuations in $E_{\theta}$ along the level A MITL. This heating and resultant turbulent character of the electron sheath differentiates the coupled MITL-convolute simulation approach used here from previous convolute simulations [4,38], where shorter

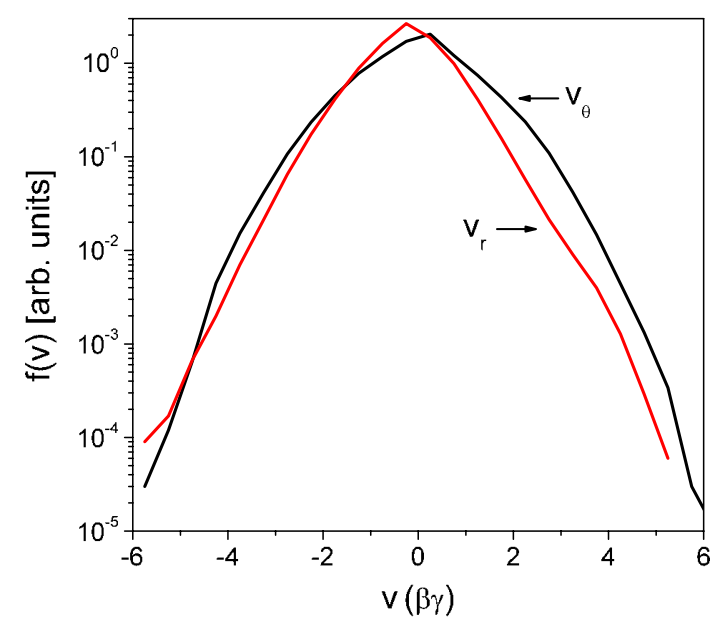

FIG. 8. Electron velocity distribution functions at $t=22 \mathrm{~ns}$ from the baseline simulation for $13<r<17 \mathrm{~cm}$ in the level A MITL. 
MITL segments upstream of the convolute likely resulted in different sheath characteristics at the beginning of the convolute.

One method to identify the locations of electron current loss to the anode hardware is to track the energy deposited on the hardware surfaces $[4,16,38]$. Figure 9 shows several images of energy deposition per nanosecond during quasiequilibrium operation on various anode surfaces. The bottom frame (d) shows the entire simulation volume. Frame (a) shows a portion of the underside of the upper anode plate. The hole in this plate indicates the connection point of the anode post. A relatively uniform region of deposition along the upper anode plate beginning at the convolute radius is observed. This region on the anode is readily accessible to electrons traveling along Poynting vector streamlines. These lines originate from both level A and level B MITLs and constitute one of the channels for current losses in the coupled MITL-convolute system.

In Figs. 9(b) and 9(c), upstream and downstream views of the anode post (respectively) show significant, localized, energy deposition patterns due to electron bombardment. On the upstream side of the post, the location of the peak of this deposition pattern coincides with the termination point of the horizontal magnetic field null shown in Fig. 4(a). Based on studies of single particle orbits in this geometry, the deposition pattern around the peak is attributed to not only electron orbits partially trapped by the null but also other families of orbits that have trajectories well outside of the horizontal null. On the downstream side of the post

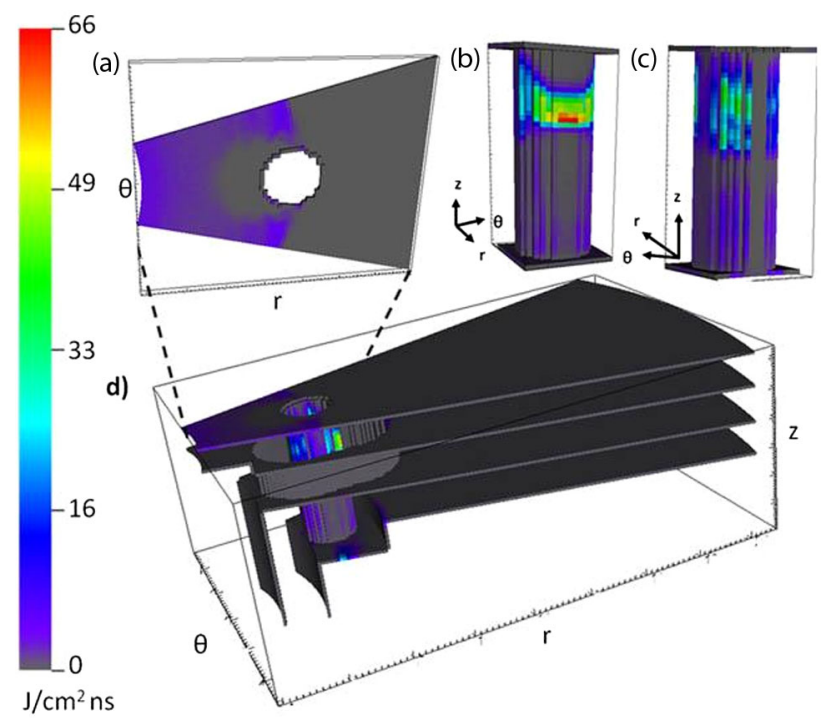

FIG. 9. Illustrations of electron energy deposition per nanosecond on anode surfaces during quasiequilibrium operation from the baseline simulation. The entire simulation volume is shown in frame (d). A portion of the upper, underside of the anode plate is shown in frame (a). Frames (b) and (c) give views of the upstream and downstream sides of the anode post, respectively. where no magnetic field null is present, electron energy deposition patterns outside of the $\theta=0$ plane are observed, due primarily to electron orbits with drift motions that pass near the anode post at grazing angles of incidence.

\section{CURRENT-LOSS SCALING}

Variations of simulation parameters described in Sec. II are examined to determine how changes to the convolute or load can impact current losses in the system. Only one change is made to the baseline case for each run to clarify current loss mechanisms.

\section{A. Current-loss scaling with voltage}

The effective loss current is plotted in Fig. 10(a) as a function of voltage for $Z_{L}=0.3 \Omega$. Here each data point is obtained from a separate simulation driven at a different operating voltage under quasiequilibrium operation. The error bars shown in Fig. 10 are approximately one-sigma values based on collected data used to calculate the loss
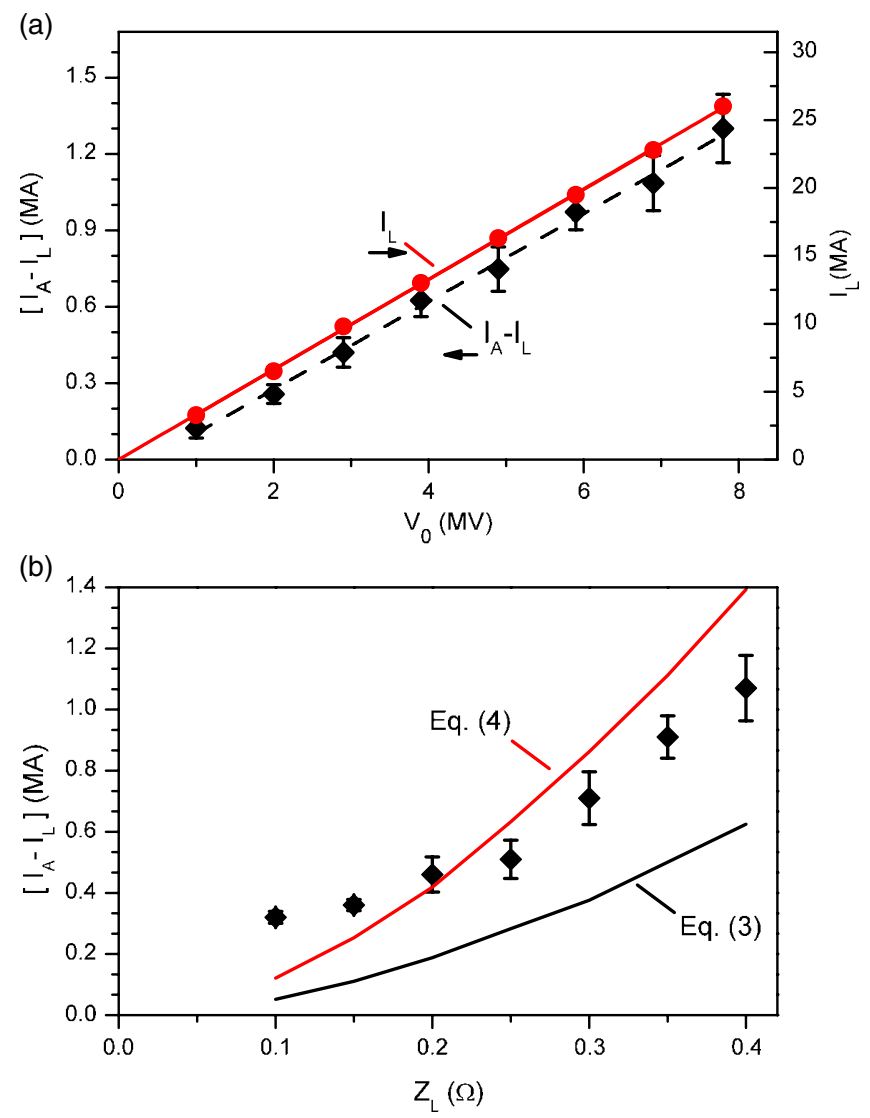

FIG. 10. (a) Loss current $\left(I_{A}-I_{L}\right.$, diamonds) and load current $\left(I_{L}\right.$, circles) as a function of equilibrium voltage from the coupled MITL-convolute simulations with $Z_{L}=0.3 \Omega$. The dashed line is a linear fit to the simulated loss current values. (b) Loss current as a function of load impedance. The solid black and red lines are calculated from Eqs. (3) and (4), respectively, using simulated values of $I_{A}$ and $I_{L}$ and assuming $Z_{v}=1.5 \Omega$. 
TABLE II. Summary of current loss scaling due to equilibrium voltage scan. (See Table I headings for more details about table entries.)

\begin{tabular}{lccccccccc}
\hline \hline$V_{0}(\mathrm{MV})$ & $I_{A}(\mathrm{MA})$ & $I_{L}(\mathrm{MA})$ & $Z_{L}(\Omega)$ & $\mathrm{f}_{l}$ & $r_{p}(\mathrm{~cm})$ & $g_{M}(\mathrm{~cm})$ & $g_{C}(\mathrm{~cm})$ & $R_{C}(\mathrm{~cm})$ & $N_{p}$ \\
\hline $\mathbf{1 . 0}$ & 3.35 & 3.27 & 0.3 & $2.5 \%$ & 0.8 & 1.0 & 1.7 & 7.6 & 12 \\
$\mathbf{2 . 0}$ & 6.71 & 6.54 & 0.3 & $2.5 \%$ & 0.8 & 1.0 & 1.7 & 7.6 & 12 \\
$\mathbf{2 . 9}$ & 10.07 & 9.78 & 0.3 & $2.9 \%$ & 0.8 & 1.0 & 1.7 & 7.6 & 12 \\
$\mathbf{3 . 9}$ & 13.45 & 13.00 & 0.3 & $3.3 \%$ & 0.8 & 1.0 & 1.7 & 7.6 & 12 \\
$\mathbf{4 . 9}$ & 16.79 & 16.24 & 0.3 & $3.3 \%$ & 0.8 & 1.0 & 1.7 & 7.6 & 12 \\
$\mathbf{5 . 9}$ & 20.19 & 19.48 & 0.3 & $3.5 \%$ & 0.8 & 1.0 & 1.7 & 7.6 & 12 \\
$\mathbf{6 . 9}$ & 23.53 & 22.71 & 0.3 & $3.5 \%$ & 0.8 & 1.0 & 1.7 & 7.6 & 12 \\
$\mathbf{7 . 8}$ & 26.96 & 26.01 & 0.3 & $3.5 \%$ & 0.8 & 1.0 & 1.7 & 7.6 & 12 \\
\hline \hline
\end{tabular}

* Baseline simulation.

current. Time-dependent variations in signal values due to vortices passing through the measurement location are the main contributor to estimated uncertainty. Larger operating voltages result in larger vortices and therefore larger uncertainty in determining an equilibrium estimate over a fixed time period. Table II lists simulated voltage, current, and impedance values corresponding to the data points in Fig. 10.

The loss current scaling with voltage is found to be approximately linear for this idealized MITL-convolute configuration. Assuming that the lower two MITL levels and lower convolute undergo the same relative loss magnitude, the values shown in Table II can be approximately doubled for direct comparison to the DPHC used on $\mathrm{Z}$ and ZR. Thus for voltages between 3 and $6 \mathrm{MV}$ (roughly spanning the $\mathrm{Z}$ and $\mathrm{ZR}$ operating regimes for a $0.3 \Omega$ load), current losses between $400 \mathrm{kA}$ and 1 MA are estimated, largely a result of electron sheath currents that are launched in the MITLs upstream of the convolute.

The loss current fraction from the data plotted in Fig. 10(a) also increases with voltage, albeit more slowly. Based on the results of 2D parallel-plate MITL simulations and analysis [46], the equilibrium sheath current is expected to increase linearly with voltage, while the sheath thickness decreases linearly. These results suggest that the current loss may be influenced by the limited spatial resolution. Since the actual current-carrying sheaths in the
MITLs are expected to be thinner than modeled here due to resolution constraints, the actual scaling of $\mathrm{f}_{l}$ is expected to be lower than indicated by Table II. Equation (3) suggests that $\mathrm{f}_{l}$ should actually be approximately independent of voltage in the limit of constant sheath thickness.

\section{B. Current-loss scaling with load impedance}

It is critical to understand how current losses scale with impedance since experimental loads typically have dynamic impedance profiles. The same forward-traveling voltage waveform was used for all runs. Table III lists individual simulations with fixed $Z_{L}$, increasing incrementally between $0.1 \Omega$ and $0.4 \Omega$. The loss current increases with load impedance, as shown in Fig. 10(b). This increase is roughly linear for $Z_{L}$ between $0.1 \Omega$ and $0.25 \Omega$ and rises more quickly for higher load impedances. These results suggest that electron power flow losses for lowimpedance loads are relatively small. Comparing the $Z_{L}=$ $0.1 \Omega$ simulation at $2.4 \mathrm{MV}$ in Table III to the $Z_{L}=0.3 \Omega$ simulations at $2.0 \mathrm{MV}$ and $2.9 \mathrm{MV}$ in Table II, it is apparent that load impedance is the dominant parameter for loss current in the simulations. Equation (3) shows that $\mathrm{f}_{l}$ should increase as the square of the load impedance, which is consistent (to within the $\pm 0.5 \%$ uncertainty of the simulation data) with the results listed in Table III at higher values of $Z_{L}$.

The collisional loss current, the red line shown in Fig. 10(b) with $Z_{L}=1.5 \Omega$, is higher than the simulation

TABLE III. Summary of current loss scaling due to load impedance scan. (See Table I headings for more details about table entries.)

\begin{tabular}{lccccccccc}
\hline \hline$V_{0}(\mathrm{MV})$ & $I_{A}(\mathrm{MA})$ & $I_{L}(\mathrm{MA})$ & $Z_{L}(\Omega)$ & $\mathrm{f}_{l}$ & $r_{p}(\mathrm{~cm})$ & $g_{M}(\mathrm{~cm})$ & $g_{C}(\mathrm{~cm})$ & $R_{C}(\mathrm{~cm})$ & $N_{p}$ \\
\hline 2.4 & 23.84 & 23.52 & $\mathbf{0 . 1 0}$ & $1.3 \%$ & 0.8 & 1.0 & 1.7 & 7.6 & 12 \\
3.4 & 22.82 & 22.46 & $\mathbf{0 . 1 5}$ & $1.6 \%$ & 0.8 & 1.0 & 1.7 & 7.6 & 12 \\
4.3 & 22.07 & 21.61 & $\mathbf{0 . 2 0}$ & $2.1 \%$ & 0.8 & 1.0 & 1.7 & 7.6 & 12 \\
5.2 & 21.37 & 20.86 & $\mathbf{0 . 2 5}$ & $2.4 \%$ & 0.8 & 1.0 & 1.7 & 7.6 & 12 \\
$5.9^{*}$ & 20.19 & 19.48 & $\mathbf{0 . 3 0}$ & $3.5 \%$ & 0.8 & 1.0 & 1.7 & 7.6 & 12 \\
6.7 & 20.18 & 19.27 & $\mathbf{0 . 3 5}$ & $4.5 \%$ & 0.8 & 1.0 & 1.7 & 7.6 & 12 \\
7.4 & 19.66 & 18.59 & $\mathbf{0 . 4 0}$ & $5.4 \%$ & 0.8 & 1.0 & 1.7 & 7.6 & 12 \\
\hline \hline
\end{tabular}

${ }^{*}$ Baseline simulation. 
results at higher values of $Z_{L}$, but smaller than the simulation results for $Z_{L} \lesssim 0.2 \Omega$. The two $f_{l}$ approximations [Eqs. (3) and (4)] cover a range of expected values from highly to poorly insulated electron sheaths in a constant impedance system. In the simulation, the transition from the MITLs to the convolute allows sheath current to be launched, limited by the effective impedance of the post hole, a type of parallel diode load. Thus, the transition from $Z_{L}$ to $Z_{L}^{2}$ scaling of the loss current is plausible. As mentioned previously, these results are constrained by spatial resolution and further study is warranted.

It is interesting to note that the relatively small loss current values at lower operating voltages shown in Fig. 10(b) are consistent with lower voltage $\mathrm{Z}$ shots using relatively low-impedance wire array loads. For example, two nominally identical $\mathrm{Z}$ shots at $13 \mathrm{MA}$ [5] resulted in roughly $0.2 \mathrm{MA}$ of loss current, consistent with the estimated equilibrium value shown in Fig. 10(b) for a fixed load impedance of $0.1 \Omega$. Of course, a detailed analysis of the loss current for these shots should include the timedependent characteristics of the electron dynamics for the rising voltage and current driving the dynamic $\left(Z_{L} \neq\right.$ constant $)$ load.

\section{Impact of geometric modifications on current loss}

A series of variations about the baseline configuration was studied including AK gap sizes, post radius, cathode hole size, convolute radial location, and the number of posts. Table IV lists results from these scans. The objective is to rapidly look for any sensitivities in $\mathrm{f}_{l}$ due to these geometric parameters. The impact of all parameter variations are discussed below.

MITL AK gaps (rows 1-5).-Larger AK gaps offer later onset of possible gap closure due to electrode plasma formation, but the increased inductance can be equally detrimental to system performance [1,2]. The loss current fraction scales with MITL impedance, load current, and anode current as predicted by Eq. (3).

Cathode plasma model (rows 6-8).-All cathodes were expanded, effectively decreasing all AK gaps to mimic the presence of dense, uniformly expanded cathode plasma. Note that this results in a decrease in the cathode hole radius. As expected, these simulations show an increase in losses over the baseline case, primarily attributable to the smaller AK gap between the cathode hole and anode post.

Post-hole AK gaps (rows 9-14). - Changing the anode post or cathode hole radius creates changes in impedance and inductance of the convolute, potentially affecting the amount of sheath disruption and liftoff. The convolute AK gap is defined as the radial distance between the upstream side of the anode post and cathode hole. Note that this is the location of the largest post-hole separation. Larger convolute AK gaps were studied in two different simulations, by reducing the anode post radius (row 9) and by increasing the cathode hole size (row 14). The former yielded a loss

TABLE IV. Summary of current loss scaling due to geometry changes. (See Table I headings for more details about table entries.)

\begin{tabular}{llcccccccccc}
\hline \hline Row & Geometry configurations & $V_{0}(\mathrm{MV})$ & $I_{A}(\mathrm{MA})$ & $I_{L}(\mathrm{MA})$ & $Z_{L}(\Omega)$ & $\mathrm{f}_{l}$ & $r_{p}(\mathrm{~cm})$ & $g_{M}(\mathrm{~cm})$ & $g_{C}(\mathrm{~cm})$ & $R_{C}(\mathrm{~cm})$ & $N_{p}$ \\
\hline 1 & MITL AK gap variation & 5.8 & 20.18 & 19.37 & 0.3 & $4.0 \%$ & 0.8 & $\mathbf{0 . 9}$ & 1.7 & 7.6 & 12 \\
2 & & $5.9^{*}$ & 20.19 & 19.48 & 0.3 & $3.5 \%$ & 0.8 & $\mathbf{1 . 0}$ & 1.7 & 7.6 & 12 \\
3 & & 5.9 & 20.11 & 19.52 & 0.3 & $2.9 \%$ & 0.8 & $\mathbf{1 . 1}$ & 1.7 & 7.6 & 12 \\
4 & & 5.9 & 20.20 & 19.66 & 0.3 & $2.7 \%$ & 0.8 & $\mathbf{1 . 2}$ & 1.7 & 7.6 & 12 \\
5 & & 5.9 & 20.09 & 19.60 & 0.3 & $2.4 \%$ & 0.8 & $\mathbf{1 . 3}$ & 1.7 & 7.6 & 12 \\
\hline 6 & Cathode plasma model & $5.9^{*}$ & 20.19 & 19.48 & 0.3 & $3.5 \%$ & 0.8 & $\mathbf{1 . 0}$ & $\mathbf{1 . 7}$ & 7.6 & 12 \\
7 & & 5.8 & 20.16 & 19.37 & 0.3 & $3.6 \%$ & 0.8 & $\mathbf{0 . 9}$ & $\mathbf{1 . 6}$ & 7.6 & 12 \\
8 & & 5.8 & 20.25 & 19.28 & 0.3 & $4.8 \%$ & 0.8 & $\mathbf{0 . 8}$ & $\mathbf{1 . 5}$ & 7.6 & 12 \\
\hline 9 & Post-hole AK gap: post radius & 5.9 & 20.13 & 19.54 & 0.3 & $2.9 \%$ & $\mathbf{0 . 2}$ & 1.0 & 2.3 & 7.6 & 12 \\
10 & & $5.9^{*}$ & 20.19 & 19.48 & 0.3 & $3.5 \%$ & $\mathbf{0 . 8}$ & 1.0 & 1.7 & 7.6 & 12 \\
11 & & 5.6 & 20.23 & 18.65 & 0.3 & $7.8 \%$ & $\mathbf{1 . 2}$ & 1.0 & 1.3 & 7.6 & 12 \\
\hline 12 & Post-hole AK gap: hole radius & 5.8 & 20.18 & 19.44 & 0.3 & $3.7 \%$ & 0.8 & 1.0 & $\mathbf{1 . 6}$ & 7.6 & 12 \\
13 & & $5.9^{*}$ & 20.19 & 19.48 & 0.3 & $3.5 \%$ & 0.8 & 1.0 & $\mathbf{1 . 7}$ & 7.6 & 12 \\
14 & & 5.9 & 20.17 & 19.50 & 0.3 & $3.3 \%$ & 0.8 & 1.0 & $\mathbf{1 . 8}$ & 7.6 & 12 \\
\hline 15 & Convolute radial position & $5.9^{*}$ & 20.19 & 19.48 & 0.3 & $3.5 \%$ & 0.8 & 1.0 & 1.7 & $\mathbf{7 . 6}$ & 12 \\
16 & & 6.0 & 20.88 & 20.03 & 0.3 & $4.1 \%$ & 0.8 & 1.0 & 1.7 & $\mathbf{9 . 6}$ & 12 \\
17 & & 5.6 & 20.64 & 18.64 & 0.3 & $9.7 \%$ & 0.8 & 1.0 & 1.7 & $\mathbf{1 5 . 2}$ & 12 \\
\hline 18 & Number of posts & $5.9^{*}$ & 20.19 & 19.50 & 0.3 & $3.5 \%$ & 0.8 & 1.0 & 1.7 & 7.6 & $\mathbf{1 2}$ \\
19 & & 5.9 & 20.15 & 19.47 & 0.3 & $3.4 \%$ & 0.8 & 1.0 & 1.7 & 7.6 & $\mathbf{1 0}$ \\
20 & & 5.8 & 20.15 & 19.54 & 0.3 & $3.0 \%$ & 0.8 & 1.0 & 1.7 & 7.6 & $\mathbf{6}$ \\
\hline \hline
\end{tabular}

*Baseline simulation. 


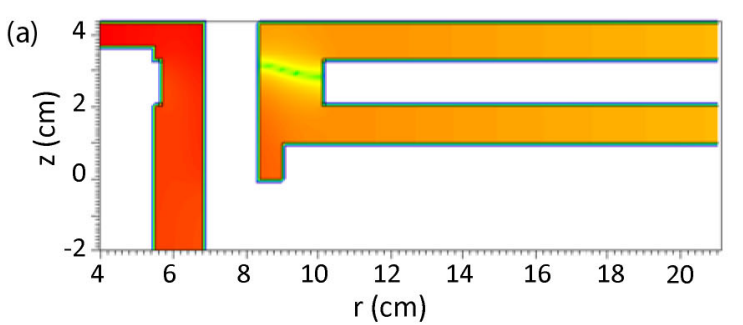

(b)
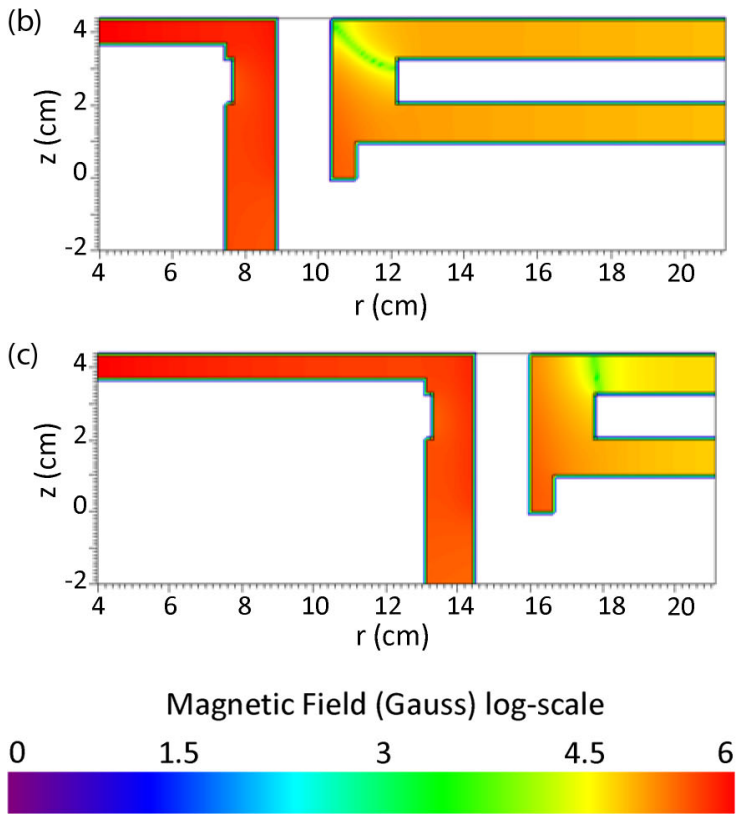

FIG. 11. Magnetic field magnitude (log scale) for the (a) $R_{C}=7.6 \mathrm{~cm}$ case, (b) $R_{C}=9.6 \mathrm{~cm}$ case, and (c) $R_{C}=15.2 \mathrm{~cm}$ case.

current decrease of $120 \mathrm{kA}$ while the later yielded only a small improvement $(\sim 40 \mathrm{kA})$.

Reducing the convolute AK gap by either increasing the post diameter or decreasing the hole radius (rows 11 and 12) allows more current to flow through the system which results in more sheath current being intercepted by electrodes in and beyond the convolute. Also note that numerical constraints on the simulation contribute, in part, to high loss current values due to the small number of cells spanning the smaller convolute AK gap. Increasing the anode post radius from $8 \mathrm{~mm}$ to $1.2 \mathrm{~cm}$ (from row 10 to row 11) resulted in approximately 2 times more loss current. These findings suggest that a larger post or smaller cathode hole leads to degraded performance, as expected.

Convolute radial position (rows 15-17).-The convolute inductance was increased by relocating the post-hole system farther out in radius, away from the central load region. Increasing the radial location of the convolute can provide additional space for larger diameter loads and reduce the current density along many electrode surfaces. With the convolute moved $2 \mathrm{~cm}$ further away from the machine axis (row 15 to row 16), the loss current fraction is moderately increased. Doubling the radial position of the convolute (row 17) yielded a loss current fraction nearly 3 times greater than that seen in the baseline case. As the convolute is moved farther away from the machine axis, the energy deposition patterns on the anode surfaces change; more electrons strike the upper and lower anode plates upstream of the post and fewer electrons strike the post itself.

To understand this dramatic increase in $\mathrm{f}_{l}$, the magnetic field null structures in the convolute for cases listed in rows 15 through 17 are plotted in Fig. 11. Frame (a) corresponds to the baseline simulation $\left(R_{C}=7.6 \mathrm{~cm}\right)$, frame (b) to $R_{C}=9.6 \mathrm{~cm}$, and frame (c) to $R_{C}=15.2 \mathrm{~cm}$. This change to the magnetic field structure allows more level A sheath electrons to intercept the magnetic field null and be lost to anode surfaces. At larger convolute radial positions the null terminates higher up the anode post, eventually connecting to the upper anode plate.

Fewer posts (rows 18-20). - The total number of posts is decreased from 12 and the baseline cathode hole and anode post dimensions are retained. Reducing the number of posts in the convolute results in an increase in the current carried in each post. This in turn improves the magnetic insulation around the posts, forcing the magnetic field null to relocate. As shown in Table IV, the current loss decreases somewhat with decreasing post number. Deposition to the individual posts also decreases with decreasing post number at the expense of additional deposition to the other anode surfaces. This change in deposition pattern is due to the relocated horizontal magnetic field null, which moved to a more vertical position as the number of posts is decreased.

Two additional simulations were conducted with modifications impacting the length of the magnetic field nulls in the convolute; these results are summarized in Table V.

TABLE V. Summary of current loss scaling due to magnetic field null length. (See Table I for more details about table entries.)

\begin{tabular}{|c|c|c|c|c|c|c|}
\hline$V_{0}(\mathrm{MV})$ & $I_{A}(\mathrm{MA})$ & $I_{L}(\mathrm{MA})$ & $Z_{L}(\Omega)$ & $\mathrm{f}_{l}$ & $\begin{array}{l}\text { Horizontal null } \\
\text { length }(\mathrm{cm})\end{array}$ & $\begin{array}{l}\text { Vertical null } \\
\text { length }(\mathrm{cm})\end{array}$ \\
\hline $5.9^{*}$ & 20.19 & 19.48 & 0.3 & $3.5 \%$ & 1.7 & 2.0 \\
\hline 5.9 & 20.19 & 19.49 & 0.3 & $3.5 \%$ & 1.0 & 2.0 \\
\hline 5.9 & 20.19 & 19.48 & 0.3 & $3.5 \%$ & 1.7 & 1.0 \\
\hline
\end{tabular}

* Baseline simulation. 
TABLE VI. Summary of current loss scaling due to ion $\left(H^{+}\right)$emission. (See Table I headings for more details about table entries.)

\begin{tabular}{|c|c|c|c|c|c|c|c|c|c|c|}
\hline Ion emission & $V_{0}(\mathrm{MV})$ & $I_{A}(\mathrm{MA})$ & $I_{L}(\mathrm{MA})$ & $Z_{L}(\Omega)$ & $\mathrm{f}_{l}$ & $r_{p}(\mathrm{~cm})$ & $g_{M}(\mathrm{~cm})$ & $g_{C}(\mathrm{~cm})$ & $R_{C}(\mathrm{~cm})$ & $N_{p}$ \\
\hline None & $5.9^{*}$ & 20.19 & 19.48 & 0.3 & $3.5 \%$ & 0.8 & 1.0 & 1.7 & 7.6 & 12 \\
\hline$\Delta T>400^{\circ} \mathrm{C}$ & 5.7 & 20.56 & 19.07 & 0.3 & $7.2 \%$ & 0.8 & 1.0 & 1.7 & 7.6 & 12 \\
\hline$r<10 \mathrm{~cm}$ & 5.6 & 20.70 & 18.68 & 0.3 & $9.5 \%$ & 0.8 & 1.0 & 1.7 & 7.6 & 12 \\
\hline$r<20 \mathrm{~cm}$ & 5.0 & 21.81 & 16.83 & 0.3 & $20.5 \%$ & 0.8 & 1.0 & 1.7 & 7.6 & 12 \\
\hline
\end{tabular}

*Baseline simulation.

The first case shortened the horizontal null by moving the anode post upstream by $0.7 \mathrm{~cm}$. The second variation raised the lower anode in the convolute region to shorten the vertical null by $1 \mathrm{~cm}$ (this change removes the vertical step in the lower anode in the convolute; see Fig. 3). Neither variation yielded a significant change to the total loss current.

\section{ANODE ION EMISSION}

Energy deposition due to electrons striking anode surfaces results in a temperature increase and eventual plasma formation [47]. A thin anode plasma is a source of SCL emitted ions. Earlier simulation work studying the impact of ions emitted from the anode surface demonstrated a relatively weak loss mechanism in the convolute section of the original $\mathrm{Z}$ accelerator. It was noted that these results constituted a lower bound on loss currents due to simulation constraints $[4,17,18]$.

The impact of ion emission from various anode components under quasiequilibrium conditions is explored.
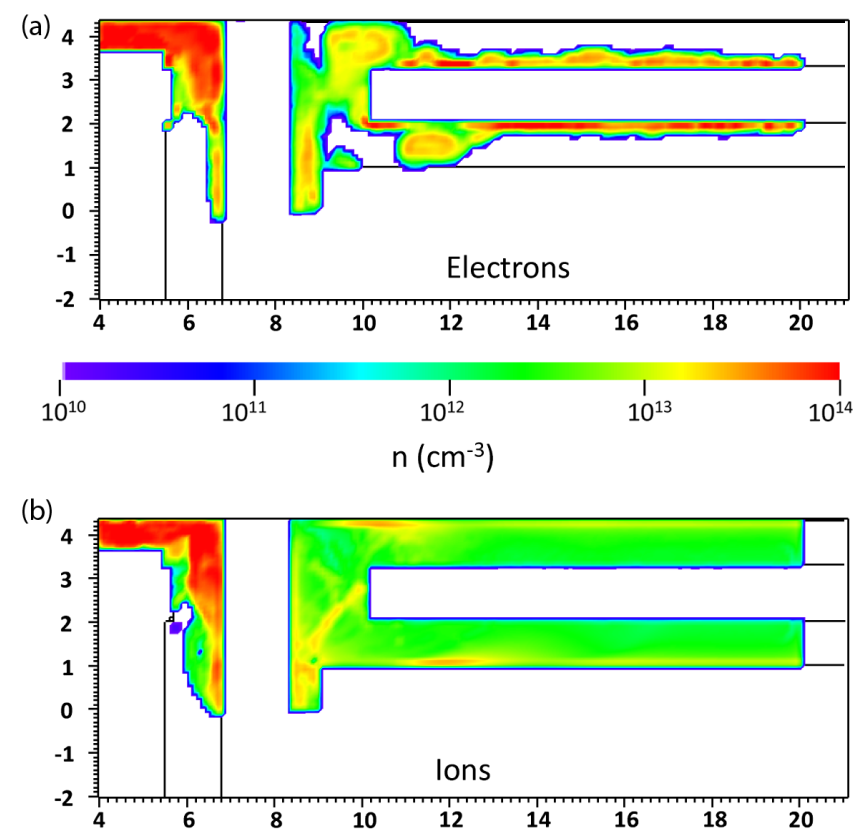

FIG. 12. Number density plots for electrons (a) and ions (b) roughly $3 \mathrm{~ns}$ after quasiequilibrium is established in a $V_{0}=$ $5.9 \mathrm{MV}, Z_{L}=0.3 \Omega$ simulation with ion emission from all anode surfaces with $r<20 \mathrm{~cm}$.
Typically ion emission is enabled for anode surfaces that undergo a $400{ }^{\circ} \mathrm{C}$ temperature increase due to electron bombardment $[47,51]$. On $\mathrm{Z}$ this typically occurs for radii less than $\sim 10 \mathrm{~cm}$ [4]. The energy deposition model used in these simulations accurately accounts for angular dependence of the incident electron at the conductor surface.

Three cases with anode SCL ion emission are examined to demonstrate additional current losses due to ion $\left(\mathrm{H}^{+}\right)$ emission. All three simulations are driven with the same baseline forward-traveling voltage waveform and have the same load impedance of $0.3 \Omega$. Pertinent simulation results can be found in Table VI and each case is discussed below. All simulations are carried out over time scales that allow for quasiequilibrium values to be obtained ( $~ 30 \mathrm{~ns})$.

For the first case, ion emission was enabled for all anode surfaces that experience a temperature increase of at least $400{ }^{\circ} \mathrm{C}$ due to $10 \mathrm{~ns}$ of quasiequilibrium electron bombardment. This results in a slowly evolving equlibrium condition, whereby a portion of the anode surfaces in the convolute and final MITL emit ions. A loss current fraction of $7.2 \%$ is found, a value roughly double that obtained for the baseline electron-only simulation. Nearly all surfaces

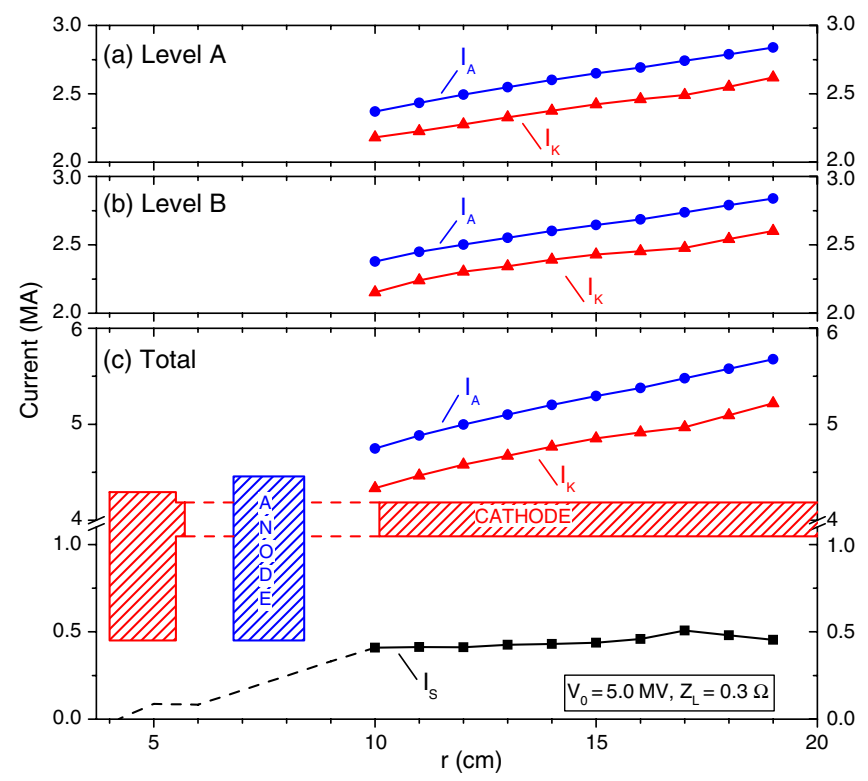

FIG. 13. Current amplitudes as a function of radius in a simulation with anode ion emission allowed from all anodes with $r<$ $20 \mathrm{~cm}$. Quasiequilibrium current amplitudes are shown for (a) MITL A, (b) MITL B, and (c) MITLs A + B. 
within the convolute region reach the emission temperature threshold, consistent with previous 3D simulations [17,21]. The losses obtained here are greater than previous results due to the establishment of an equilibrium state.

The next case allows ion emission from all anode surfaces in the convolute region, i.e. $r<10 \mathrm{~cm}$. This results in a loss current fraction of $9.5 \%$. Losses here are somewhat higher than in the previous case, as expected, since ion emission is required from all anode surfaces and is not limited by temperature requirements.

In the third test case, ion emission is switched on for all anode surfaces with a radius less than $20 \mathrm{~cm}$, and therefore includes ion emission in the A and B MITLs. This gives an upper bound to $\mathrm{f}_{l}(20.5 \%)$ obtained in this study. Figure 12 shows electron (a) and ion (b) number densities roughly $3 \mathrm{~ns}$ after quasiequlibrium conditions are established. As a result of ions crossing the AK gaps in the MITLs, both $I_{A}$ and $I_{K}$ decrease linearly with radius along the MITL section as shown in Fig. 13. While both values decrease, the electron sheath remains insulated and the sheath current [black line in Fig. 13(c)] is only modestly reduced in MITLs A and B in the presence of the ions. The relatively low density of the ions in the MITLs $\left(\sim 10^{12} \mathrm{~cm}^{-3}\right)$ does not strongly modify the higher density electron sheath $\left(\sim 10^{14} \mathrm{~cm}^{-3}\right)$.

\section{SUMMARY AND DISCUSSION}

Idealized, 3D, quasiequilibrium power flow simulations of a coupled MITL-convolute system have been conducted to study current loss scaling. The simulation parameters are based on the successful MITL-convolute designs used on the $\mathrm{Z}$ and $\mathrm{ZR}$ accelerators. By a simplified configuration consisting of only the upper two MITL levels and a single post-hole convolute, the simulations have been explicitly designed to enable rapid turnaround. Scaling information learned here will be applied to design studies pertaining to vacuum MITL-convolute systems.

In the limit of electron-only operation, sheath current loss scaling under quasiequilibrium operation has been identified. The locations of the main current loss regions are qualitatively consistent with Poynting vector streamline trajectories that extend from the upstream MITLs through the convolute to the final downstream MITL. Current-loss estimates obtained here are consistent with previous simulations of electron power flow in the $Z$ convolute $[4,17,21]$. The electron-only model assumes clean metal surfaces under which bulk or contaminant electrode plasmas do not evolve.

The loss current is found to scale linearly with operating voltage for this idealized MITL-convolute model. This is likely influenced by limited resolution of the simulations as $\mathrm{f}_{l}$ should be roughly independent of voltage in the limit of a constant sheath thickness and the majority of the electron sheath launched in the MITLs upstream of the convolute is not ideal. Scaling of $\mathrm{f}_{l}$ with load impedance is also found to be linear for $Z_{L}<0.25 \Omega$ with a larger increase for higher values. Load impedance is found to be a dominating parameter for determining $\mathrm{f}_{l}$.

In addition to voltage and load impedance scaling studies, a series of simple geometric changes were explored, all of which utilized a $0.3 \Omega$ load. The geometric variations included changing the anode post size and the cathode plate thickness. Simple variations that produced the greatest net reduction in the loss current included increasing the MITL AK gaps, reducing the anode post size, and using fewer anode posts. The combination of such geometric changes may reduce $\mathrm{f}_{l}$ but improvements are not guaranteed. For example, combining two of the changes listed above [larger MITL AK gaps $(1.3 \mathrm{~cm})$ and smaller diameter anode posts $(2 \mathrm{~mm})$ ], results in a loss current fraction of $1.7 \%$, lower than the loss current fraction due to either individual change (this result is not included in the Table IV). Note that any combination of two or more simple geometric changes to the convolute may not result in an increased efficacy because of changes to magnetic null structures, electron energy deposition patterns, etc.

Ion emission from anode surfaces in the vicinity of the convolute increases the loss current. Adding ion emission to the MITLs upstream of the convolute dramatically increases the current loss due to uninsulated ions crossing the AK gap throughout the simulation volume; however, the time-dependent turn-on of these MITL-launched ions is not treated self-consistently in this equilibrium model. Further analysis is required to quantify the physical processes that would introduce anode emitted ions in the Z MITLs.

Under the idealized assumptions explored here, it is found that in the absence of ion emission the vacuum post-hole convolute is efficient when the load impedance is much less than the MITL impedance.

\section{ACKNOWLEDGMENTS}

The authors would very much like to thank J. L. Porter, M. K. Matzen, G. R. McKee, and L. X. Schneider at Sandia National Laboratories for invaluable contributions. Numerical simulation results presented here were carried on computer facilities at Sandia and Voss Scientific. Sandia National Laboratories is a multiprogram laboratory operated by Sandia Corporation, a wholly owned subsidiary of Lockheed Martin Company, for the U.S. Department of Energy's National Nuclear Security Administration under Contract No. DE-AC04-94AL85000.

\section{APPENDIX A: COMMENTS ON NUMERICALLY UNDERRESOLVED CURRENT SHEATHS}

The spatial resolution of the 3D, EM, fully kinetic simulations in this article is sufficient to accurately calculate the electromagnetic field in the absence of charged particles. The time step of the simulations is sufficiently 
small to resolve $\omega_{\mathrm{ce}}$ and $\omega_{\mathrm{pe}}$ and satisfies the Courant condition. A sufficient number of particles are used to provide statistically meaningful results. Within the artificial numerical construct of the simulations, charge, momentum, and energy are conserved, and the coupled MaxwellLorentz equations are solved correctly.

The spatial resolution of the simulations is not sufficient to resolve electron and ion sheaths as calculated by classical models of a MITL [49,52]. None of the simulations described herein resolve these sheaths. See discussion following Eq. (2) for an example. Time constraints motivate the use of such a low-resolution approximation. Each of the parallel simulations with particles described in this article requires up to five days of calendar time to complete. For example, accurately modeling a $70 \mu \mathrm{m}$-thick electron sheath would require reducing the cell size from $1 \mathrm{~mm}$ to $\sim 5 \mu \mathrm{m}$. To resolve electron dynamics everywhere would require reducing each dimension of each cell in the simulation by a factor of $\sim 200$.

This appendix briefly considers how underresolving a charged-particle sheath in a MITL may impact simulated values of the sheath current, sheath thickness, and sheathelectron energy. To obtain estimates of these effects, consider the following example. Assume that an electron sheath is formed adjacent to a MITL cathode and

$$
t_{\text {sheath }} \ll t_{\text {cell }} \ll g_{M},
$$

where $t_{\text {sheath }}$ is the thickness of the sheath, $t_{\text {cell }}$ is the cell thickness used to model the sheath, and $g_{M}$ is the MITL AK gap. The simplifying assumptions are made that the electric field at the cathode is identically zero and the electron charge density is constant across the sheath. Under these conditions, the average electric and magnetic fields in the cell closest to the cathode would be approximately the same as they would be when

$$
t_{\text {sheath }}=t_{\text {cell }} \ll g_{M} .
$$

The charge per unit MITL area would also be approximately the same. Hence the sheath current, which is a function of the $\boldsymbol{E} \times \boldsymbol{B}$ drift velocity and total charge, would be approximately the same. This conclusion is consistent with Fig. 10, which suggests that the simulated sheath current falls within the range given by analytic estimates. However, $t_{\text {sheath }}$ and (in the relativistic limit) kinetic energy of the electrons at the edge of the sheath under the first set of conditions would both be a factor of $t_{\text {sheath }} / t_{\text {cell }}$ greater than the values obtained under the second set of conditions.

Although simulations that underresolve a chargedparticle sheath do not correctly model the particle orbits within the sheath, such simulations are expected to provide useful scaling information, and (when $t_{\text {cell }} \ll g_{M}$ ) reasonable estimates of the total charge in a sheath, characteristic $\boldsymbol{E} \times \boldsymbol{B}$ drift velocity of the sheath particles, and total sheath current.

\section{APPENDIX B: ERRORS DUE TO CHARGED PARTICLES CROSSING THE LOAD OUTLET BOUNDARY}

Charged particles leaving a simulation through the outlet boundary in PIC simulations potentially alter the calculated currents and voltage. The simulation outlet [53] accounts only for the total potential difference and 1D wave transmitting across the boundary and does not recognize the presence of individual charges. For relatively small current densities, these effects are typically small and can be neglected. Two test simulations were completed to assess the impact of typical sheath currents leaving the outlet boundary.

In the test simulations, the final transmission line was extended by connecting the radial line to a coaxial line and a radial electric field of $1 \mathrm{GV} / \mathrm{cm}$ was applied in this coaxial region, resulting in all particles being diverted to conductor surfaces prior to reaching the outlet boundary. The magnitude of the electric field was empirically chosen to overcome the large magnetization of the electrons in the simulation. Sheath current in the final transmission line is considered to be lost and does not contribute to load currents, so artificially forcing these particles to strike conductor surfaces does not change the way they are accounted for in the current calculation. The two test simulations consisted of an electron-only case and an electron-ion case.

Results from these test simulations are in good agreement with the results quoted in the paper. The electrononly simulation results showed no measurable difference in $I_{\text {loss. }}$. The electron-ion test simulation results showed an increase in $I_{\text {loss }}$ of $\sim 120 \mathrm{kA}$, or an increase of $0.6 \%$ in $\mathrm{f}_{l}$.

[1] W. A. Stygar, M. E. Cuneo, D. I. Headley, H. C. Ives, R. J. Leeper, M. G. Mazarakis, C. L. Olson, J. L. Porter, T. C. Wagoner, and J.R. Woodworth, Phys. Rev. ST Accel. Beams 10, 030401 (2007).

[2] J.P. Martin, M.E. Savage, T.D. Pointon, and M. A. Gilmore, Phys. Rev. ST Accel. Beams 12, 030401 (2009).

[3] R.B. Spielman, C. Deeney, G. A. Chandler, M. R. Douglas, D. L. Fehl, M. K. Matzen, D. H. McDaniel, T. J. Nash, J. L. Porter, T. W. L. Sanford, J. F. Seaman, W. A. Stygar, K. W. Struve, S. P. Breeze, J.S. McGurn, J. A. Torres, D. M. Zagar, T. L. Gilliland, D. O. Jobe, J. L. McKenney, R. C. Mock, M. Vargas, T. Wagoner, and D. L. Peterson, Phys. Plasmas 5, 2105 (1998).

[4] T. D. Pointon, W. A. Stygar, R. B. Spielman, H. C. Ives, and K. W. Struve, Phys. Plasmas 8, 4534 (2001).

[5] W. A. Stygar, P. A. Corcoran, H. C. Ives, R. B. Spielman, J. W. Douglas, B. A. Whitney, M. A. Mostrom, T.C. Wagoner, C.S. Speas, T.L. Gilliland, G. A. Allshouse, R.E. Clark, G.L. Donovan, T.P. Hughes, D. R. Humphreys, D. M. Jaramillo, M. F. Johnson, J. W. Kellogg, R. J. Leeper, F. W. Long, T. H. Martin, T. D. Mulville, M. D. Pelock, B. P. Peyton, J. W. Poukey, J. J. Ramirez, P. G. Reynolds, J. F. Seamen, D. B. Seidel, A. P. 
Seth, A. W. Sharpe, R. W. Shoup, J. W. Smith, D. M. Van De Valde, and R. W. Wavrik, Phys. Rev. ST Accel. Beams 12, 120401 (2009).

[6] R. B. Spielman, W. A. Stygar, J. F. Seamen, F. Long, H. Ives, R. Garcia, T. Wagoner, K. W. Struve, M. Mostrom, I. Smith, P. Spence, and P. Corcoran, in Proceedings of the 11th IEEE International Pulsed Power Conference, 1997, edited by G. Cooperstein and I. Vitkovitsky (IEEE, Piscataway, NJ, 1997), p. 709.

[7] P. A. Corcoran, J. W. Douglas, I. D. Smith, P. W. Spence, W. A. Stygar, K. W. Struve, T. H. Martin, R. B. Spielman, and H.C. Ives, in Proceedings of the 11th IEEE International Pulsed Power Conference, 1997, edited by G. Cooperstein and I. Vitkovitsky (IEEE, Piscataway, NJ, 1997), p. 466.

[8] R. J. Garcia, H. C. Ives, K. W. Struve, R. B. Spielman, T.H. Martin, M.L. Horry, R. Wavrik, and T.F. Jaramillo, in Proceedings of the 11th IEEE International Pulsed Power Conference, 1997, edited by G. Cooperstein and I. Vitkovitsky (IEEE, Piscataway, NJ, 1997), p. 1614.

[9] H. C. Ives, D. M. Van De Valde, F. W. Long, J. W. Smith, R. B. Spielman, W. A. Stygar, R. W. Wavrick, and R. W. Shoup, Proceedings of the 11th IEEE International Pulsed Power Conference, 1997, edited by G. Cooperstein and I. Vitkovitsky (IEEE, Piscataway, NJ, 1997), p. 1602.

[10] M. A. Mostrom, T. P. Hughes, R. E. Clark, W. A. Stygar, and R.B. Spielman, in Proceedings of the 11th IEEE International Pulsed Power Conference, 1997, edited by G. Cooperstein and I. Vitkovitsky (IEEE, Piscataway, NJ, 1997), p. 460.

[11] R. W. Shoup, F. Long, T. H. Martin, R. B. Spielman, W. A. Stygar, M. A. Mostrom, K. W. Struve, H. Ives, P. Corcoran, and I. Smith, in Proceedings of the 11th IEEE International Pulsed Power Conference, 1997, edited by G. Cooperstein and I. Vitkovitsky (IEEE, Piscataway, NJ, 1997), p. 1608.

[12] I. D. Smith, P. A. Corcoran, W. A. Stygar, T. H. Martin, R. B. Spielman, and R. W. Shoup, in Proceedings of the 11th IEEE International Pulsed Power Conference, 1997, edited by G. Cooperstein and I. Vitkovitsky (IEEE, Piscataway, NJ, 1997), p. 168.

[13] K. W. Struve, T. H. Martin, R. B. Spielman, W. A. Stygar, P. A. Corcoran, and J. W. Douglas, in Proceedings of the 11th IEEE International Pulsed Power Conference, 1997, edited by G. Cooperstein and I. Vitkovitsky (IEEE, Piscataway, NJ, 1997), p. 162.

[14] W. A. Stygar, R. B. Spielman, G. O. Allshouse, C. Deeney, D. R. Humphreys, H. C. Ives, F. W. Long, T. H. Martin, M. K. Matzen, D. H. McDaniel, C. W. Mendel, Jr., L. P. Mix, T. J. Nash, J. W. Poukey, J. J. Ramirez, T. W. L. Sanford, J. F. Seamen, D. B. Seidel, J. W. Smith, D. M. Van De Valde, R. W. Wavrik, P.A. Corcoran, J.W. Douglas, I. D. Smith, M. A. Mostrom, K. W. Struve, T. P. Hughes, R. E. Clark, R. W. Shoup, T. C. Wagoner, T. L. Gilliland, and B. Peyton, in Proceedings of the 11th IEEE International Pulsed Power Conference, 1997, edited by G. Cooperstein and I. Vitkovitsky (IEEE, Piscataway, NJ, 1997), p. 591.

[15] T.P. Hughes and R.E. Clark, Mission Research Corp. Report No. MRC/ABQ-R-2005, 1998. (Available from NTIS, order number PB2001-104866).
[16] T.P. Hughes and R.E. Clark, Mission Research Corp. Report No. MRC/ABQ-R-2005, 2000. (Available from NTIS, order number PB2001-104868).

[17] T. P. Hughes, R. E. Clark, B. V. Oliver, R. A. St. John, and W. A. Stygar, Mission Research Corp. Report No. MRC/ ABQ-R-2066, 2002. (Available from NTIS, order number PB2003-100707).

[18] T. D. Pointon and W. A. Stygar, in Proceedings of the 13th IEEE International Pulsed Power Conference, 2001, edited by B. Reinovsky and M. Newton (IEEE, Piscataway, NJ, 2001), p. 1696.

[19] D. H. McDaniel, M. G. Mazarakis, D. E. Bliss, J. M. Elizondo, H. C. Harjes, H. C. Ives, D. L. Kitterman, J. E. Maenchen, T. D. Pointon, S.E. Rosenthal, D. L. Smith, K. W. Struve, W. A. Stygar, E. A. Weinbrecht, D. L. Johnson, and J.P. Corely, in Proceedings of the 5th International Conference on Dense Z-Pinches, 2002, edited by J. Davis (AIP, New York, 2002), p. 23.

[20] T. D. Pointon and M. E. Savage, in Proceedings of the 15th IEEE International Pulsed Power Conference, 2005, edited by J. Maenchen (IEEE, Piscataway. NJ, 2005), p. 151.

[21] T.D. Pointon, W.L. Langston, and M.E. Savage, in Proceedings of the 16th IEEE International Pulsed Power Conference, 2007, edited by E. Schamiloglu and F. Peterkin (IEEE, Piscataway, NJ, 2007), p. 165.

[22] T. D. Pointon and D. B. Seidel, in Proceedings of the 17th IEEE International Pulsed Power Conference, 2009, edited by R. Curry (IEEE, Piscataway, NJ, 2009), p. 1159.

[23] M. E. Savage, L. F. Bennett, D. E. Bliss, W. T. Clark, R. S. Coats, J. M. Elizondo, K. R. LeChien, H. C. Harjes, J. M. Lehr, J. E. Maenchen, D. H. McDaniel, M. F. Pasik, T. D. Pointon, A. C. Owen, D. B. Seidel, D. L. Smith, B. S. Stoltzfus, K. W. Struve, W. A. Stygar, L. K. Warne, J. R. Woodworth, C. W. Mendel, K. R. Prestwich, R. W. Shoup, D. L. Johnson, J. P. Corley, K. C. Hodge, T. C. Wagoner, and P.E. Wakeland, in Proceedings of the 16th IEEE Pulsed Power and Plasma Science Conference, 2007, edited by E. Schamiloglu and F. Peterkin (IEEE, Piscataway, NJ, 2007), p. 979.

[24] D. V. Rose, D. R. Welch, C. L. Miller, R. E. Clark, E. A. Madrid, C. B. Mostrom, T. C. Wagoner, J. K. Moore, W. A. Stygar, J. E. Bailey, T. J. Nash, G. A. Rochau, and D. B. Sinars, Phys. Rev. ST Accel. Beams 13, 040401 (2010).

[25] D. V. Rose, D. R. Welch, E. A. Madrid, C. L. Miller, R. E. Clark, W. A. Stygar, M.E. Savage, G. A. Rochau, J.E. Bailey, T.J. Nash, M.E. Sceiford, and K.W. Struve, Phys. Rev. ST Accel. Beams 13, 010402 (2010).

[26] M. S. Di Capua and D. G. Pellinen, J. Appl. Phys. 50, 3713 (1979).

[27] D. V. Rose, D. R. Welch, R. E. Clark, E. A. Madrid, C. L. Miller, C. Mostrom, W. A. Stygar, M. E. Cuneo, C. A. Jennings, B. Jones, D. J. Ampleford, and K. W. Struve, in Proceedings of the 17th IEEE International Pulsed Power Conference, 2009, edited by F. Peterkin (IEEE, Piscataway, NJ, 2009), p. 23.

[28] J. M. Creedon, J. Appl. Phys. 48, 1070 (1977).

[29] R. W. Stinnett, M. A. Palmer, R. B. Spielman, and R. Bengston, IEEE Trans. Plasma Sci. 11, 216 (1983).

[30] W. A. Stygar H. C. Ives, D. L. Fehl, M. E. Cuneo, M. G. Mazarakis, J. E. Bailey, G. R. Bennett, D. E. Bliss, G. A. Chandler, R. J. Leeper, M. K. Matzen, D. H. McDaniel, 
J. S. McGurn, J. L. McKenney, L. P. Mix, D. J. Muron, J. L. Porter, J. J. Ramirez, L. E. Ruggles, J. F. Seamen, W. W. Simpson, C. S. Speas, R. B. Spielman, K. W. Struve, J. A. Torres, R. A. Vesey, T. C. Wagoner, T. L. Gilliland, M. L. Horry, D. O. Jobe, S. E. Lazier, J. A. Mills, T. D. Mulville, J. H. Pyle, T. M. Romero, J. J. Seamen, and R. M. Smelser, Phys. Rev. E 69, 046403 (2004).

[31] V. V. Ivanov, P. J. Laca, B. S. Bauer, R. Presura, V. I. Sotnikov, A.L. Astanovitskiy, B. Le Galloudec, J. Glassman, and R. A. Wirtz, IEEE Trans. Plasma Sci. 32, 1843 (2004).

[32] Y. L. Bakshaev, A. V. Bartov, P. I. Blinov, A. S. Chernenko, S. A. Dan'ko, Y. G. Kalinin, A. S. Kingsep, V. D. Korolev, V. I. Mizhiritskii, V.P. Smirnov, A. Yu. Shashkov, P. V. Sasorov, and S. I. Tkachenko, Plasma Phys. Rep. 33, 259 (2007).

[33] T. P. Hughes, R. E. Clark, B. V. Oliver, T. D. Pointon, and W. A. Stygar, in Proceedings of the 14th IEEE International Pulsed Power Conference, 2003, edited by M. Gieesselmann and A. Neuber (IEEE, Piscataway, NJ, 2003), p. 622.

[34] T. C. Wagoner, W. A. Stygar, H.C. Ives, T. L. Gilliland, R. B. Spielman, M.F. Johnson, P. G. Reynolds, J. K. Moore, R. L. Mourning, D. L. Fehl, K. E. Androlewicz, J.E. Bailey, R.S. Broyles, T.A. Dinwoodie, G.L. Donovan, M.E. Dudley, K. D. Hahn, A. A. Kim, J. R. Lee, R. J. Leeper, G. T. Leifeste, J. A. Melville, J. A. Mills, L.P. Mix, W. B. S. Moore, B.P. Peyton, J.L. Porter, G. A. Rochau, G. E. Rochau, M. E. Savage, J. F. Seamen, J. D. Serrano, A. W. Sharpe, R. W. Shoup, J. S. Slopek, C. S. Speas, K. W. Struve, D. M. Van De Valde, and R.M. Woodring, Phys. Rev. ST Accel. Beams 11, 100401 (2008).

[35] D. B. Seidel (private communication).

[36] T.P. Hughes (private communication).

[37] C.A. Jennings, J.P. Chittenden, M.E. Cuneo, W. A. Stygar, D. J. Ampleford, E. M. Waisman, M. Jones,
M.E. Savage, K. R. LeChien and T.C. Wagoner, IEEE Trans. Plasma Sci. 38, 529 (2010).

[38] D. V. Rose, D. R. Welch, T. P. Hughes, R. E. Clark, and W. A. Stygar, Phys. Rev. ST Accel. Beams 11, 060401 (2008).

[39] M. R. Gomez, Ph.D. dissertation, University of Michigan, 2011.

[40] J.P. VanDevender, R. W. Stinnett, and R. J. Anderson, Appl. Phys. Lett. 38, 229 (1981).

[41] R. W. Stinnett and T. Stanley, J. Appl. Phys. 53, 3819 (1982).

[42] D. S. Prono, H. Ishizuka, E. P. Lee, B. W. Stallard, and W. C. Tuner, J. Appl. Phys. 52, 3004 (1981).

[43] T. D. Pointon, J. Appl. Phys. 66, 2879 (1989).

[44] E. W. Gray and R. W. Stinnett, J. Appl. Phys. 61, 5222 (1987).

[45] D. R. Welch, D. V. Rose, M. E. Cuneo, R. B. Campbell, and T. A. Mehlhorn, Phys. Plasmas 13, 063105 (2006).

[46] D. V. Rose, T. C. Genoni, R. E. Clark, D. R. Welch, and W. A. Stygar, Phys. Plasmas 18, 033108 (2011).

[47] T. W. L. Sanford, J.A. Halbleib, J. W. Poukey, A. L. Pregenzer, R. C. Pate, C.E. Heath, R. C. Mock, G. A. Mastin, D. C. Ghiglia, T. J. Roemer, P. W. Spence, and G. A. Prolux, Jpn. J. Appl. Phys. 66, 10 (1989).

[48] J. T. Crow and G. D. Peterson, IEEE Trans. Plasma Sci. 11, 219 (1983).

[49] C. W. Mendel, Jr., D. B. Seidel, and S. E. Rosenthal, Laser Part. Beams 1, 311 (1983).

[50] W. A. Stygar, T. C. Wagoner, H. C. Ives, P. A. Corcoran, M.E. Cuneo, J.W. Douglas, T.L. Gilliland, M. G. Mazarakis, J. J. Ramirez, J. F. Seamen, D. B. Seidel, and R. B. Spielman, Phys. Rev. ST Accel. Beams 9, 090401 (2006).

[51] A. E. Blaugrund, Phys. Fluids 20, 1185 (1977).

[52] C. W. Mendel, Jr., J. A. Swegle, and D. B. Seidel, Phys. Rev. A 32, 1091 (1985).

[53] B. Goplen, L. Ludeking, D. Smithe, and G. Warren, Comput. Phys. Commun. 87, 54 (1995). 